Universidade de Brasília (UnB)

Faculdade de Economia, Administração, Contabilidade e Ciência da Informação e Documentação (FACE)

Programa de Pós-Graduação em Administração (PPGA)

FABIANA DA SILVEIRA CAPUTO

MUDANÇAS OCORRIDAS PELA IMPLANTAÇÃO DE

UNIVERSIDADE CORPORATIVA NO SETOR ELÉTRICO

BRASILEIRO: A PERCEPÇÃO DE SEUS EMPREGADOS

Brasília - DF

2008 
FABIANA DA SILVEIRA CAPUTO

\section{MUDANÇAS OCORRIDAS PELA IMPLANTAÇÃO DE UNIVERSIDADE CORPORATIVA NO SETOR ELÉTRICO BRASILEIRO: A PERCEPÇÃO DE SEUS EMPREGADOS}

Monografia apresentada ao Programa de
Pós-Graduação em Administração (PPGA) da
Faculdade de Economia, Administração,
Contabilidade e Ciência da Informação e
Documentação (FACE), da Universidade de Brasília
(UnB), como requisito parcial à obtenção do grau de
Especialista em Gestão de Pessoas.

Orientadora: Prof ${ }^{a}$ Dra. Miramar Ramos Maia Vargas

Brasília - DF 
A minha vó, Djanira, que muito nos deixou saudade.

Aos meus pais, Lucia e Geraldo, que mesmo longe estiveram sempre presente, me apoiando $e$ me incentivando na busca do conhecimento $e$ da aprendizagem.

Aos meus irmãos, Geovane e Jair, pelo carinho e afeto.

Ao meu namorado, Rodrigo, pelo amor, amizade $e$ compreensão nos momentos de angústia.

À toda minha família e, em especial a Tia Terezinha, à Danila e Daniela, pela amizade, companhia e dedicação em me ajudar a superar os momentos dificeis. 


\section{AGRADECIMENTOS}

Primeiramente a Deus pelo dom da vida e pela força em continuar e não desistir no meio do caminho!

A minha orientadora, Miramar Ramos Maia Vargas, que desde o início me incentivou e me apoiou na realização e conclusão deste importante estudo e que sem ela não seria possível a finalização deste trabalho.

As colegas da Especialização que estiveram sempre presente Daniele Marchese, Maryangela Carol, Juliana Ribeiro, Tatiana Carneiro e em especial a Fabíola Cristina Ferreira dos Santos que muito contribuiu para a realização deste trabalho.

Aos colegas da Eletronorte que disponibilizaram atenção necessária à realização da pesquisa e o fornecimento de informações importantes para a conclusão deste estudo: Eden Brasília de Assunção Damasceno, Ana Carolina Fernandes Costa, André Naves Cangirana, Claudia Maria Pereira, Hugo Delgado Laranjeira, Wania Mara de Mello Aguiar e Maja Meira. 


\section{RESUMO}

O presente trabalho teve como objetivo geral estudar as mudanças organizacionais decorrentes da implantação de uma universidade corporativa. Os objetivos específicos foram: a) Investigar, na percepção dos empregados de uma empresa pública do setor elétrico brasileiro, se ocorreram mudanças organizacionais com a implantação da universidade corporativa; b) fornecer subsídios à organização pesquisada sobre o processo de consolidação da sua universidade corporativa. A pesquisa foi conduzida na empresa "Centrais Elétricas do Norte do Brasil S/A" - Eletronorte e utilizou a técnica de "survey", com aplicação da "Escala de percepção de mudança organizacional causada pela introdução de universidade corporativa (UC)". Participaram da pesquisa 270 sujeitos. O instrumento foi disponibilizado em formato eletrônico com a utilização do Software Lime Survey, na página da Universidade Corporativa Eletronorte (Ucel), e as respostas criaram um arquivo que, posteriormente, foi transferido para o banco de dados do Statistical Package for Social Sciences (SPSS). Os resultados apontaram que, dos quatros fatores do instrumento, dois obtiveram médias acima de 4,00 - "Estímulo à educação continuada" e "Estabelecimento de parcerias entre a organização e instituições de ensino". Foram encontradas correlações significativas entre algumas variáveis demográficas e os fatores que formavam o instrumento. Os resultados encontrados se mostraram mais otimistas do que alguns relatados pela literatura com relação às mudanças organizacionais causadas pela implantação de universidades corporativas.

Palavras-chave: Universidade Corporativa; Mudanças Organizacionais. 


\section{LISTA DE FIGURAS}

Figura 1 - Localização da UCEL no Organograma da Eletronorte. 


\section{LISTA DE QUADROS}

Quadro 1 - Percepção da Mudança Organizacional na visão de diversos autores............. 22

Quadro 2 - Definições de mudanças organizacionais................................................... 23

Quadro 3 - Tipologias da Mudança......................................................................... 25

Quadro 4 - Missão, Visão e Valores da Eletronorte..................................................... 30 


\section{LISTA DE TABELAS}

Tabela 1 - Gênero dos Sujeitos................................................................... 31

Tabela 2 - Escolaridade dos Sujeitos.......................................................... 32

Tabela 3 - Faixa Etária............................................................................... 33

Tabela 4 - Tempo de Serviço na Eletronorte...................................................... 33

Tabela 5 - Categoria Funcional..................................................................... 34

Tabela 6 - Lotação....................................................................................... 35

Tabela 7 - Função dos Participantes da Pesquisa................................................ 36

Tabela 8 - Consistência interna dos Fatores: comparação entre as duas aplicações do instrumento de pesquisa............................................................... 39

Tabela 9 - Média e Desvio padrão dos Fatores do Instrumento............................ 40

Tabela 10 - Média e Desvio padrão Itens dos Fatores 3 e 4 .................................. 41

Tabela 11 - Correlações entre as Variáveis Demográficas (VI’s) e os Fatores do

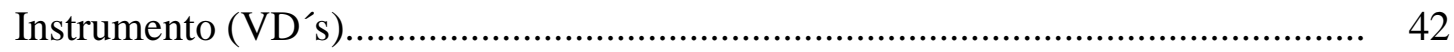


INTRODUÇÃ

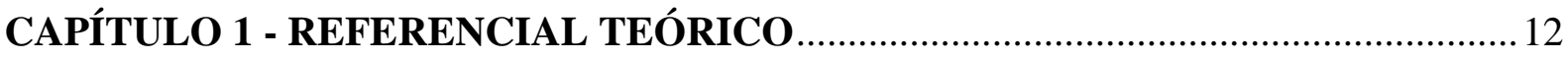

1.1 - Universidade Corporativa .............................................................................. 12

1.1.1 Origem e definição de universidade corporativa ................................................... 12

1.1.2 - Características das universidades corporativas ……………………………….... 14

1.1.3 - Objetivos da universidade corporativa .............................................................. 18

1.1.4 - Diferenças entre universidade corporativa e área de treinamento e

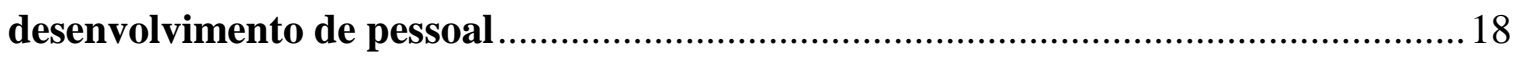

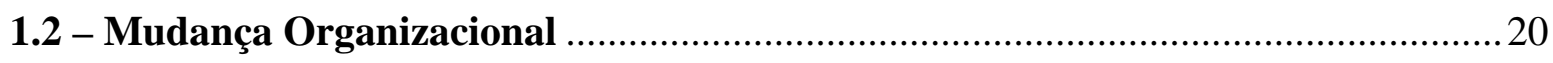

1.2.1 - Definições de mudança organizacional ............................................................21

1.2.2 - Tipologia da mudança organizacional ..........................................................2 23

1.3 - Mudança organizacional e universidade corporativa ............................................2

CAPÍTULO 2 - ASPECTOS METODOLÓGICOS DA PESQUISA …………………......29

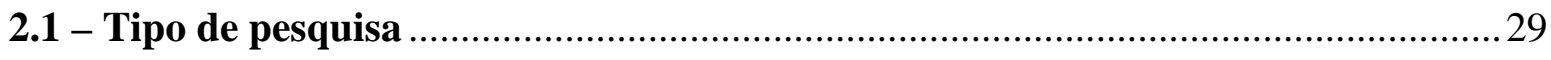

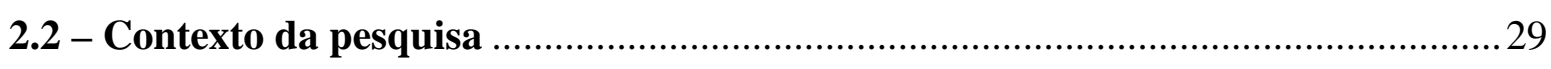

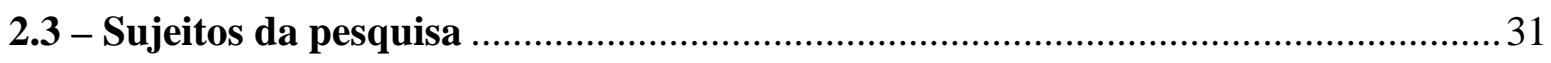

2.4 - Instrumento

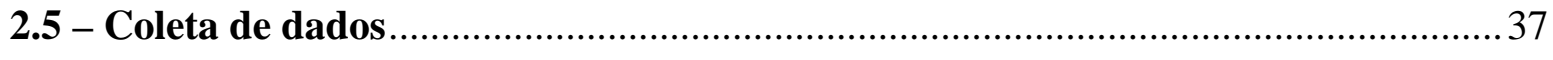

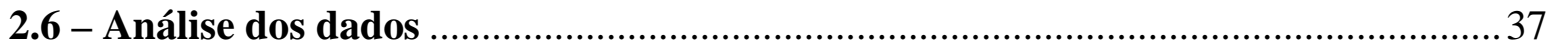

CAPÍTULO 3 - APRESENTAÇÃO E DISCUSSÃO DOS RESULTADOS …………........38

3.1 - A Ucel e as mudanças organizacionais na Eletronorte .............................................38

3.1.1 - Consistência interna dos itens do instrumento...................................................39

3.1.2 - Média e desvio padrão dos fatores do instrumento …………………………......4 40

3.1.3 - Estudo de correlações ..................................................................................... 42

3.2 - Subsídios gerados pelos resultados da Pesquisa ……………………………….....4

CONCLUSÃO

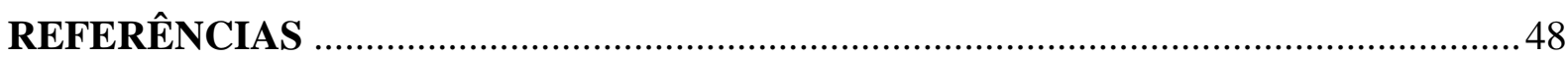

ANEXO A - POP-UP DE DIVULGAÇÃO DA PESQUISA …………………………......51

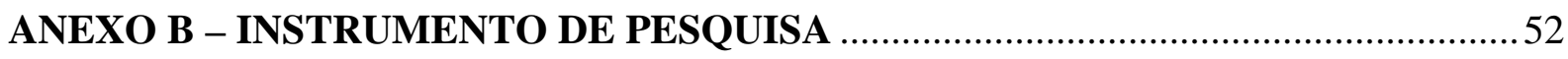




\section{INTRODUÇÃO}

O mundo vem passando por constantes mudanças que fazem com que as organizações tenham a necessidade de se adaptarem a um ambiente cada vez mais competitivo, incerto e com rápidas transformações.

Alperstedt e Plonski (2001) destacam que as organizações são obrigadas a reagirem a essas mudanças, definindo e redefinindo seus negócios. Essas modificações do negócio são frutos das revoluções tecnológicas, do novo papel dos governos e, também, da globalização. Ainda segundo esses autores, a competição no mercado está cada vez maior, na medida em que o protecionismo vai cedendo lugar à privatização e as barreiras comerciais e alfandegárias estão sendo substituídas pelo livre comércio.

Com isso, as organizações têm que repensar sua forma de agir e de se destacarem frente aos seus concorrentes. Para Alperstedt e Plonski (2001), uma das maneiras que as organizações encontraram para conseguir um diferencial competitivo é a valorização do conhecimento. Assim, hoje as organizações estão em um processo de aprendizagem contínua, em busca da atualização constante do seu quadro de pessoal.

Paralelamente a essas mudanças, o conceito de emprego também foi alterado com o passar dos anos. Segundo Vitelli (2000), o trabalho deixou de significar segurança e passou a ser um desenvolvimento pessoal. Nesse sentido, houve uma mudança na visão de "carreira" dentro das organizações. Antes, o crescimento profissional do empregado era gerenciado pela própria organização, dentro de uma visão paternalista, característica do paradigma mecanicista. Hoje, o indivíduo é o principal responsável pelo gerenciamento da sua carreira. Cabe a ele identificar suas competências e ir à procura de ferramentas para suprir suas necessidades de aprendizado.

Ainda segundo Vitelli (2000), hoje o profissional é responsável pela sua empregabilidade e, portanto, precisa estar apto do ponto de vista técnico, gerencial, intelectual, humano e social para solucionar problemas cada vez mais complexos. Isso significa a necessidade dele assumir um compromisso com a aprendizagem contínua. $\mathrm{O}$ mercado valoriza indivíduos com diversas habilidades e iniciativas, não esquecendo que a carreira e, conseqüentemente o desenvolvimento, pertence ao profissional.

Na visão de Vargas (2003a), essa demanda contínua por aprendizagem, aliada aos avanços tecnológicos, levou a uma mudança na forma como as organizações estavam treinando e desenvolvendo o seu quadro de pessoal. Expressões como "universidade corporativa", "e-learning" e outras foram inseridas no dia-a-dia do contexto organizacional. A preocupação vigente, segundo a autora, não é a de seguir um modismo, mas de buscar 
soluções para o problema de treinar e desenvolver empregados em menos tempo, com menos recursos e a intervalos cada vez menores.

Um breve olhar na literatura da área mostra que, principalmente a partir de 1980, começou a crescer o número de universidades corporativas, tanto nos Estados Unidos como em outros países. No Brasil, é possível observar um crescimento a partir de 1990, com a criação de várias universidades corporativas tanto no setor público como na iniciativa privada.

Por se tratar de um fenômeno relativamente novo, ainda se conhece pouco sobre as mudanças trazidas pelas universidades corporativas para as empresas que as implantaram. Algumas universidades corporativas ainda estão em fase de implantação ou não foram totalmente implementadas.

A criação de uma universidade corporativa, segundo a literatura da área, promove uma série de mudanças na forma como as organizações planejam e executam suas ações de treinamento, desenvolvimento e educação. Entretanto, conforme afirmado anteriormente, ainda existe pouca pesquisa mostrando até que ponto essas mudanças realmente aconteceram nas organizações que implantaram universidade corporativa.

Assim, por ser ainda grande a lacuna de conhecimentos na área, o presente estudo pretende investigar o seguinte problema de pesquisa: "Na percepção dos empregados, a implantação de uma universidade corporativa provoca mudanças organizacionais?" Para responder a essa questão, foram estabelecidos os seguintes objetivos:

\section{Objetivo Geral}

- Estudar as mudanças organizacionais decorrentes da implantação de uma universidade corporativa.

\section{Objetivos Específicos}

- Investigar, na percepção dos empregados de uma empresa pública do setor elétrico brasileiro, se ocorreram mudanças organizacionais com a implantação da universidade corporativa.

- Fornecer subsídios à organização pesquisada sobre o processo de consolidação da sua universidade corporativa.

Segundo Meister (1999), uma universidade corporativa nada mais é do que uma unidade educativa dentro das organizações. Contudo, afirma a autora, ela possui uma missão 
mais ampla do que as áreas tradicionais de treinamento de pessoal. Elas representam um esforço das organizações no sentido de desenvolver nos empregados de todos os níveis, as qualificações, o conhecimento e as competências necessários ao sucesso no trabalho atual e futuro.

Vargas (2003b) chamou a atenção para o crescimento, nos últimos anos, do número de universidades corporativas, tanto nos Estados Unidos, país em que se originou a idéia, como também nos países da Europa, Ásia e Oceania. No Brasil, observa a autora, muitas organizações do setor privado e do setor público também começaram a adotar a idéia. Entretanto, destaca Vargas, a produção científica não acompanhou a expansão do fenômeno e, no Brasil, ainda são poucas as publicações disponíveis sobre o tema.

Autores como Marcondes e Paiva (2001) conduziram uma pesquisa para verificar o diferencial existente entre uma área tradicional de treinamento de pessoal e uma universidade corporativa, tendo encontrado pouca diferença entre elas. Dengo (2002), em outra pesquisa, também apontou resultados pouco otimistas com relação às diferenças trazidas na implantação de uma universidade corporativa.

A escassez de literatura sobre o tema e os resultados ainda pouco otimistas relatados em algumas pesquisas justificam a relevância deste estudo. 


\section{CAPÍTULO 1 - REFERENCIAL TEÓRICO}

Este Capítulo fará uma breve revisão da literatura sobre dois temas específicos universidade corporativa e mudança organizacional. Com relação ao primeiro tema serão abordados alguns aspectos gerais que caracterizam uma universidade corporativa e a diferença dos modelos das áreas tradicionais de treinamento e desenvolvimento de pessoal (T\&D). No segundo tema será revisada a literatura da área de mudança organizacional, com foco nos diferentes conceitos e tipologias propostos pelos autores.

\section{1 - Universidade Corporativa}

\subsubsection{Origem e definição de universidade corporativa}

Barley (2002 apud VARGAS, 2003b) narra que as universidades corporativas têm sua origem no século passado como forma de continuar a educação dos empregados iniciada a partir de 1914. As organizações e indústrias procurando preencher suas próprias necessidades de treinamento desenvolveram seus departamentos de treinamento e desenvolvimento com objetivo de oferecer a sua força de trabalho o desempenho de habilidades importantes para a execução de suas atividades com eficiência e perfeição. Os departamentos de treinamento passaram a ter o objetivo de ensinar as tarefas, padrões e rotinas importantes para que os empregados se desempenhassem bem em uma economia baseada em habilidades.

Barley esclarece que na medida em que os Estados Unidos passavam de uma economia baseada em habilidades para uma economia baseada na informação, focada no conhecimento, a pouca efetividade e presteza dos centros de treinamento e desenvolvimento começaram a dificultar o crescimento e desenvolvimento da empresa. Assim, na primeira metade do século $\mathrm{XX}$, as áreas de recursos humanos precisaram refletir sobre seus desempenhos, pois eram vistas como onerosas, desnecessárias e ineficientes e precisavam, mesmo assim, começar a lidar com necessidades específicas de aprendizagem demandadas por um novo ambiente organizacional.

Para equilibrar essa reputação, afirma Barley (2002 apud VARGAS, 2003b), as áreas de treinamento começaram a mudar sua forma de atuação. Elas começaram a se utilizar modelos de administração com o objetivo de renovar e revolucionar a forma de lidar com os processos de aprendizagem no meio empresarial, pois perceberam que alguns elementos importantes ao negócio, como a estratégia e o valor, não estavam sendo focalizados. Para isso, o treinamento deveria alinhar a missão aos objetivos empresariais e provar que era capaz de 
influenciar a empresa a atingi-los. Surgem então, as universidades corporativas, um modelo desenhado para que:

- os funcionários possam compreender qual é o negócio da empresa;

- os funcionários saibam quem são seus clientes, concorrentes e fornecedores;

- a empresa saiba quais são as melhores práticas adotadas por outras empresas;

- a área de treinamento entenda qual é o seu real papel para ajudar no alcance dos objetivos organizacionais.

Allen (2002 apud VARGAS, 2003b) esclarece que uma universidade corporativa pode ser definida como uma entidade educacional, uma ferramenta estratégica desenhada para que a empresa possa alcançar sua missão através da condução de ações que desenvolva sabedoria, conhecimento e aprendizagem individual ou organizacional. Ela não é desenhada para todos os tipos de organizações. As organizações muito pequenas ou as que dependem mais de tecnologia automatizada do que das pessoas, talvez não tenham muito ganho com a implantação de uma universidade corporativa. Ainda de acordo com esse autor, a razão para se criar uma universidade corporativa é para que ela possa ajudar no cumprimento da missão organizacional.

Tarapanoff (2004) destaca que a universidade corporativa pode ser entendida como um "instituto de aprendizado" que busca o desenvolvimento das corporações, representando inovação na área de educação corporativa.

Para Éboli (1996), a missão de uma universidade corporativa é formar e desenvolver talentos na gerência dos negócios, desenvolvendo a gestão do conhecimento organizacional que inclui geração, assimilação, difusão e aplicação. Os principais objetivos são o desenvolvimento e a instalação das competências técnicas, profissionais e gerenciais e para difundi-la é importante que a organização identifique a competência que realmente será seu diferencial competitivo e consequentemente responsável pelo seu sucesso.

Assim, esclarece Éboli, uma universidade corporativa tem a missão de desenvolver pessoas com ações alinhadas ao planejamento estratégico da organização, além de oferecer crescimento e aprimoramento constante aos indivíduos com visão no presente e no futuro. Ela tem como objetivo transformar a empresa numa organização em constante aprendizado em que o conhecimento é visto como vantagem competitiva, um diferencial que pode colocá-la à frente de suas concorrentes no mercado.

Para Meister (1999), cinco grandes forças sustentam a expansão de universidade corporativa, as quais são: 
- Emergência da organização não-hierárquica - organizações mais enxutas e flexíveis conseguem responder mais rapidamente às demandas atuais do mundo corporativo;

- Surgimento da economia do conhecimento - nova forma de gerenciamento da informação no trabalho. Mais pessoas estão realizando trabalhos que demandam maior conhecimento;

- Redução do prazo de validade do conhecimento - a demanda por aprendizado contínuo é imposta pela pouca validade do conhecimento. As pessoas necessitam substituir tudo o que sabem em um curto prazo de tempo para continuarem atuar em suas carreiras;

- Mudança do conceito de empregabilidade - não há mais a garantia de um emprego vitalício. O emprego depende das qualificações e conhecimentos adquiridos pelo individuo ao longo da sua carreira;

- Mudança do conceito de educação nas organizações - as organizações passaram a ajudar o indivíduo a complementar sua formação acadêmica e a construir uma cadeia de aprendizado contínuo.

\subsection{2 - Características das universidades corporativas}

As universidades corporativas estão presentes nos diversos setores e são tão variadas quanto as empresas as quais estão inseridas. Peak (1997) discorre sobre alguns pontos de diferentes disposições organizacionais que influenciam nos modelos de universidades corporativas:

\section{a) origem do investimento}

Universidades Corporativas precisam de grandes investimentos por parte das organizações aos quais pertencem, porém o retorno sobre esse investimento é difícil de ser mensurado motivo pelo qual as universidades corporativas estão mais presentes em empresas maiores. Visando resolver esse problema, empresas utilizam de consórcios com outras empresas não concorrentes compartilhando necessidades de treinamento comum e com objetivo de reduzir custos.

A utilização de um modo diferente de receita também serve de elemento motivador para que as universidades corporativas estendam treinamentos aos seus componentes da cadeia de valor de sua organização. Uma importante fonte de renda para as universidades corporativas, que tem objetivo de sua independência financeira, é o licenciamento de 
programas a seus fornecedores e clientes. A maioria das universidades corporativas não recebe recursos de fontes externas, no entanto, fazem parcerias com outras empresas a fim de diminuir custos para a organização.

\section{b) espaço físico}

A maioria das universidades corporativas utiliza suas próprias instalações físicas e outras utilizam as instalações de ensino superior tradicionais em forma de consórcio. Há ainda aquelas que não utilizam nenhum arranjo físico concreto porque estão fundamentadas em redes eletrônicas e, assim, independem de espaços físicos, constituindo as organizações virtuais. Existem ainda as que estão num meio termo, mesclam atividades presencias com atividades a distancia, são as universidades corporativas que contam com recursos da mídia eletrônica para a promoção das atividades de ensino-aprendizagem.

\section{c) créditos reconhecidos e outorga de diplomas}

As organizações e suas universidades corporativas por si só não têm o poder de emissão de certificados, apenas instituições de ensino superior. Nesse sentido, diversas parcerias entre organizações e instituições de ensino superior tradicionais são estabelecidas.

\section{d) composição do corpo docente}

A composição do corpo docente varia pois algumas universidades corporativas entendem que somente professores universitários titulados são capazes de ministrar cursos, outras contam com executivos da empresa e/ou consultores externos e há ainda, as que utilizam-se dos próprios empregados da empresa após submetidos a treinamentos específicos para desenvolver habilidades didáticas.

\section{e) clientela}

Diversas universidades corporativas oferecem treinamentos para pessoas externas a organização, estendendo suas ações educacionais aos clientes, fornecedores, franqueados, outras empresas e até mesmo a comunidade em geral. Essa expansão de atendimento é resultante do sucesso obtido pelo programa junto aos próprios empregados e motivado pela possibilidade de diminuição de custos. Assim, a universidade corporativa pode tornar-se um grande potencial de centro de obtenção de lucros, sendo uma importante alternativa de captação de recursos financeiros para a organização.

$\mathrm{Na}$ visão de Meister (1999), para ser bem sucedida, uma universidade corporativa necessita contemplar os seguintes elementos: 
- Ter o comprometimento da cúpula da organização com o empreendimento;

- Fazer alianças de aprendizagem com instituições educacionais formais;

- Utilizar, de forma intensiva, as tecnologias da informação para expandir as possibilidades de aprendizagem;

- Operar como uma unidade de negócios.

Ainda segundo a autora, outro fator importante das universidades corporativas é o seu currículo básico, o qual, em geral, tem sido desenvolvido com base no que ficou conhecido como os três "Cs":

- Cidadania corporativa - o currículo deve servir para desenvolver a cidadania corporativa dos trabalhadores da organização.

- Contexto - o currículo deve proporcionar uma estrutura contextual para a empresa.

- Competências básicas - o currículo deve ajudar na criação de competências básicas entre os funcionários da organização.

Para Alperstedt (2000), a universidade corporativa é sustentada por três características: a) desenvolvimento de competências essenciais ao negócio da empresa; b) não restrição dos serviços educacionais aos funcionários, e c) estabelecimento de parcerias com instituições de ensino superior ou aferição de diplomas de forma independente.

Segundo Alperstedt e Plonski (2001) um fator importante é que a prestação de serviços educacionais disponibilizados pela universidade corporativa não se restringe aos funcionários podendo participar fornecedores, clientes, franqueados, comunidade e outros da cadeia de valor da organização.

Leal (2003) afirma que as universidades corporativas organizam-se em torno de alguns princípios, são eles:

- Oferecer oportunidades de aprendizagem que dêem sustentação às questões organizacionais mais importantes;

- Considerar o modelo da universidade corporativa um processo e não um espaço físico destinado à aprendizagem;

- Elaborar um currículo que incorpore os 3Cs: cidadania corporativa, estrutura contextual e competências básicas;

- Treinar a cadeia de valores e parceiros, inclusive clientes, distribuidores, fornecedores de produtos terceirizados; 
- Passar do treinamento conduzido pelo instrutor para vários formatos de apresentação da aprendizagem;

- Encorajar e facilitar o envolvimento dos líderes com o aprendizado, inclusive como facilitadores;

- Passar do modelo de financiamento corporativo por alocação para autofinanciamento pelas unidades de negócio;

- Assumir um foco global no desenvolvimento de soluções de aprendizagem;

- Criar um sistema de avaliação dos resultados e também investimento; e

- Utilizar a universidade corporativa para obter vantagem competitiva e atuar em novos mercados.

Leal aponta outro ponto muito importante na universidade corporativa que é o vínculo que ela tenta criar entre a organização e seus funcionários, tentando obter um controle afetivo e também um controle comportamental nos treinamentos, aperfeiçoando as competências comportamentais.

Segundo Éboli (2004), de uma maneira geral, as universidades corporativas enfatizam as seguintes metas:

- Difundir a idéia de que capital intelectual será o fator de diferenciação das empresas;

- Despertar nos talentos a vocação para o aprendizado e a responsabilidade por seu processo de autodesenvolvimento;

- Incentivar, estruturar e oferecer atividades de autodesenvolvimento; e

- Motivar e reter os melhores talentos, contribuindo para o aumento da realização e felicidade pessoal.

Outra característica interessante das universidades corporativas, segundo Éboli, é que elas operam com base em um sistema de desenvolvimento de pessoas pautado pela gestão de competências. Para a autora, uma maneira de avaliar se realmente o projeto de universidade corporativa, proposto pela organização, "tem fôlego" é observar se a empresa também está trabalhando com o conceito de competências em outros subsistemas da gestão de recursos humanos e não apenas na parte de treinamento e desenvolvimento de pessoal. 
Tarapanoff (2004) acredita que as melhores universidades corporativas são aquelas que focalizam ajudar a organização a atingir sua missão. A autora afirma que a universidade corporativa deve pensar estrategicamente desenvolvendo planos para o cumprimento da missão organizacional.

\subsection{3 - Objetivos da universidade corporativa}

Na concepção de Éboli (1999), os objetivos de uma universidade corporativa são o desenvolvimento e a instalação das competências profissionais, técnicas e gerenciais consideradas essenciais para viabilizar os negócios da organização.

Alperstedt (2000) atribui como objetivo de uma universidade corporativa a existência de um programa de capacitação que garanta mensagem unificada e linguagem comum, com vistas a aumentar as qualificações, conhecimentos e competências dos indivíduos que trabalham nas organizações.

Vitelli (2000) destaca que a utilização do nome universidade corporativa traduz seu objetivo de proporcionar aos seus participantes o conteúdo para o seu sucesso e crescimento profissional, sendo o centro onde é gerado e disseminado o conhecimento explícito, um local de aprendizado contínuo conferindo vantagem competitiva para a empresa.

Para Alperstedt e Plonski (2001), a universidade corporativa "tem como objetivo principal a manutenção de empregados com elevado potencial de agregação de valor representando uma fonte potencial de vantagens competitivas”.

Pode-se dizer, a partir dos parágrafos anteriores, que o objetivo da universidade corporativa é desenvolver os indivíduos de forma a atuarem nos negócios essenciais da organização de modo que ela sobressaia frente aos concorrentes uma vez que será através da universidade corporativa que os empregados agregararão maior valor aos conhecimentos, habilidades e atitudes.

\subsection{4 - Diferenças entre universidade corporativa e área de treinamento e desenvolvimento de pessoal}

De acordo com Meister (1999) as universidades corporativas surgiram em razão de que as empresas precisam que seus empregados aprendam rápido, acompanhando as demandas atuais por conhecimento. Elas vêm com a missão de alinhar planejamento empresarial com iniciativas de treinamento, considerando os valores organizacionais, contextos e competências essenciais, estando assim diretamente ligadas ao negócio da 
organização. Para a autora, as universidades corporativas são muito mais do que um "departamento de treinamento revestido com um novo nome", pois elas representam um esforço para desenvolver em empregados de todos os níveis, as qualificações, os conhecimentos e as competências necessárias ao sucesso no trabalho atual e futuro.

Meister (1999) esclarece que a universidade corporativa funciona de modo mais centralizado e com um escopo bem mais amplo do que as áreas tradicionais de treinamento e desenvolvimento de pessoal. Isto porque, uma vez instalada, a universidade atua como se fosse um guarda-chuva estratégico que comporta todas as ações de treinamento e desenvolvimento. A universidade corporativa tem a missão de alinhar aos objetivos organizacionais todos os envolvidos no processo e apresentar soluções de aprendizagem continua com importância estratégica para cada conjunto de cargos ou funções.

Ainda segundo Meister, um departamento de treinamento é reativo, descentralizado e serve a uma ampla audiência, enquanto a universidade corporativa tem orientação proativa e centralizada para o desenvolvimento de soluções de aprendizagem para cada negocio da organização. Isto significa que os programas de treinamento nos departamentos de treinamento e desenvolvimento de pessoas ocorrem de acordo com a necessidade as vezes identificadas até em um determinado departamento e com tópicos genéricos, enquanto nas universidades corporativas as ações de treinamento são permanentes e voltadas para o futuro, antecipando e gerando necessidades ainda que voltadas para cada negócio da própria organização.

Outra característica apontada por Meister (1999) que evidencia uma diferença entre o departamento de treinamento e a universidade corporativa está no fato de que o primeiro é direcionado para habilidades técnicas imediatamente necessárias à execução das atividades exigidas pelo trabalho atual, enquanto que a universidade corporativa não fica restrita a essas habilidades. A universidade corporativa envolve, também, conhecimento de valores e cultura da corporação, da indústria em que a organização opera, seus fornecedores, clientes, concorrentes, toda sua cadeia de valor, além das competências básicas exigidas pelo negócio da organização.

Meister esclarece, também, que os departamentos de treinamento são administrados como qualquer outra unidade da organização, ou seja, sendo inteiramente financiados por ela, enquanto que as universidades corporativas são consideradas, na maioria dos casos, como uma unidade de negócio, capazes de captar recursos para a organização.

Uma outra característica marcante das universidades corporativas é que elas estão promovendo parcerias com instituições de ensino superior para melhorar a titulação acadêmica e o conhecimento especializado de seus empregados. 
Allen (2002, apud VARGAS, 2003b) destaca que apesar do treinamento ser uma atividade viável da universidade corporativa, por si só um departamento de treinamento não se qualifica como uma universidade corporativa. Segundo o autor, isso ocorre porque os departamentos de treinamento geralmente não vinculam suas atividades à missão e aos objetivos estratégicos da organização.

Uma universidade corporativa desempenha suas atividades em sentido inverso do que é atualmente a função de treinamento, afirmam Vargas e Abbad (2006). As áreas tradicionais de treinamento trabalham de forma centralizada e com vários programas independentes, enquanto uma universidade corporativa atua de maneira mais centralizada, porém com uma visão bem mais abrangente de toda a organização.

\section{2 - Mudança Organizacional}

Atualmente as organizações e seus empregados enfrentam diversos desafios, precisam acompanhar as mudanças estabelecidas pela nova Era da Informação e do Conhecimento, bem como as demandas impostas pela globalização.

Segundo Albrecth (1988), vive-se hoje uma fase caracterizada por mudanças em todas as esferas da vida social, da política aos valores sociais e da cultura às formas de sociabilidade. Por isso, as organizações estão em busca de uma moderna estrutura dinâmica e flexível já que precisam se auto-ajustar com a finalidade de acompanhar as reestruturações sociais que vêem ocorrendo.

Wind e Main (1988) compararam organizações tradicionais com as emergentes do século atual e verificaram as seguintes características nessas últimas organizações: muito flexíveis, orientadas pela visão, focadas em valores, capazes de aprender, funcionam em redes, e, no entanto, são interdependentes e altamente focadas no cliente. Essas características também são observadas por Hammer (2003) o qual afirma que as organizações emergentes vivem em um mundo cheio de confusões, desafios e insucessos característicos do mundo humano. Assim, este tipo de organização está cada vez mais se distanciando da disciplina e da rigidez, características fortes das organizações tradicionais.

De acordo com Hernandez e Caldas (2000), a mudança organizacional passou a ser uma das principais atividades para empresas e instituições em todo mundo. As organizações mudam para fazer face à crescente competitividade, cumprir novas leis ou regulamentações, introduzir novas tecnologias ou, para atender variações nas preferências de consumidores ou de parceiros. 
Autores como Lima e Bressan (2003) afirmam que o foco principal para que ocorra uma mudança é a melhoria do desenvolvimento organizacional, uma vez que é ela quem dará as respostas para as demandas organizacionais.

Para se entender melhor as mudanças organizacionais causadas pela implantação de universidades corporativas, faz-se necessária uma breve revisão das definições encontradas na literatura. Neiva (2004) chama a atenção para o fato de que o conceito de mudança organizacional é problemático, pois existem diversos questionamentos do que seria realmente o fenômeno da mudança.

\subsection{1- Definições de mudança organizacional}

Alguns autores, como Araújo (1982), definem a mudança organizacional com base nos componentes organizacionais: estrutura, tecnologia e estratégia. Para o autor, mudança organizacional é uma alteração significativa, articulada, planejada e operacionalizada por pessoal interno ou externo da organização, com apoio ou supervisão da administração superior e que alcance integralmente os componentes de cunho comportamental, estrutural, tecnológico e estratégico.

Porras e Robertson (1992, apud LIMA; BRESSAN, 2003) conceituam mudança organizacional com base em dois critérios: categoria e ordem. No primeiro critério, a mudança pode ser planejada ou não. A mudança planejada é considerada resultado de intervenções do "desenvolvimento organizacional" (DO) e da procura do desempenho organizacional ou a da elevação do desempenho do individuo, por meio de mudanças de comportamentos no trabalho.

Com relação ao segundo critério apontado por Porras e Robertson, ele pode ser de primeira ou segunda ordem. Esses autores definem mudança como um conjunto de teorias, valores, estratégias e técnicas cientificamente embasadas com objetivo de mudança planejada do ambiente de trabalho a fim de propiciar o desenvolvimento individual e desempenho organizacional, focalizando a mudança no comportamento do individuo.

Segundo Nascimento e Bulgacov (1999), a mudança organizacional pode ser entendida como a busca do equilíbrio entre o ambiente e a organização, a qual se tornou sinônimo de competitividade e sucesso. Para ele, um fator muito importante na mudança organizacional é o papel do gerente, a responsabilidade que ele possui sobre a efetividade da mudança. Esses autores analisaram a percepção de mudança organizacional segundo a visão de vários outros e uma síntese dessa análise será apresentada, a seguir, no Quadro 1: 


\begin{tabular}{|c|l|}
\hline Autor & \multicolumn{1}{|c|}{ Percepção da Mudança Organizacional } \\
\hline $\begin{array}{c}\text { Hinings e Greenwood } \\
(1989)\end{array}$ & $\begin{array}{l}\text { Percebem a mudança dentro de dois conceitos - arquétipos organizacionais e track } \\
\text { (movimento). Utilizando esses conceitos os autores conseguem perceber a mudança } \\
\text { como agrupamento de estruturas das organizações que vão se movimentando de } \\
\text { acordo com a necessidade. }\end{array}$ \\
\hline $\begin{array}{c}\text { Laughlin } \\
(1991)\end{array}$ & $\begin{array}{l}\text { O autor percebe que além do papel do gerente na mudança, o ambiente também tem } \\
\text { participação fundamental, pois é ele quem provoca desequilíbrio, necessitando, assim, } \\
\text { mudar para atingir novamente o equilíbrio perdido. }\end{array}$ \\
\hline Wilson & $\begin{array}{l}\text { Percebe a mudança organizacional com dois extremos - mudança planejada e } \\
\text { mudança emergente. O autor vê que a mudança planejada é percebida pela sequêencia } \\
\text { lógica dos passos e a mudança emergente verifica-se que as forças internas e externas } \\
\text { que traçam o caminho da mudança. }\end{array}$ \\
\hline Scott & $\begin{array}{l}\text { O autor percebe uma separação do ambiente técnico e institucional. O primeiro é } \\
\text { caracterizado pela busca de recursos e know-how. O segundo busca uma legitimação } \\
\text { social. }\end{array}$ \\
\hline
\end{tabular}

Quadro 1 - Percepção da mudança organizacional na visão de vários autores.

Fonte: Nascimento e Bulgacov (1999)

Robbins (1999) considera a mudança uma atividade intencional, proativa e voltada para o alcance de metas organizacionais. Ele explica que mudanças intencionais podem levar a organização a melhorar a capacidade de adaptação ao ambiente e, também, influencia na mudança de comportamentos de seus empregados.

$\mathrm{Na}$ definição de Bruno-Faria (2003) mudança organizacional são alterações, planejadas ou não, ocorridas na organização, decorrente de acontecimentos internos e/ou externos a ela, que traz alguma modificação nos resultados e/ou nas relações interpessoais no trabalho.

Lima e Bressan (2003) reuniram um conjunto de definições encontradas na literatura sobre mudança organizacional, as quais serão apresentadas no Quadro 2, a seguir: 
Qualquer modificação, planejada ou não, nos componentes organizacionais formais e informais mais relevantes (pessoas, estrutura, produtos, processos e cultura); modificação que seja significativa e atinja a maioria dos membros da organização e tenha por objetivo a melhoria do desempenho organizacional em resposta às demandas internas e externas.

Qualquer alteração, planejada ou não, ocorrida na organização, decorrente de fatores internos e/ou externos à mesma, que traz algum impacto nos resultados e/ou nas relações entre pessoas no trabalho.

Qualquer transformação de natureza estrutural, estratégica, cultural, tecnológica, humana ou de outro componente, capaz de gerar impacto em parte ou no conjunto da organização.

Bressan

(2001)

Bruno-Faria (2003)

Wood Jr. (2000) Robbins

Atividades intencionais proativas e direcionadas, para obtenção das metas organizacionais. (1999)

Resposta da organização às transformações que vigoram no ambiente, com intuito de manter a congruência entre os componentes organizacionais (trabalho, pessoas, arranjos/estrutura e cultura).

Nadler et al. (1994)

Acontecimento temporal estritamente relacionado a uma lógica, ou ponto de vista individual, que possibilita às pessoas pensarem e falarem sobre a mudança que percebem.

Seqüência de eventos que se desdobram durante a existência da entidade organizacional e que relatam um tipo específico de mudança.

Conjunto de teorias, valores, estratégias e técnicas cientificamente embasadas objetivando mudança planejada do ambiente de trabalho com objetivo de levar o desenvolvimento individual e o desempenho organizacional.

Abstração de segunda ordem, ou seja, trata-se do registro de impressões sobre a relação entre várias dinâmicas.

Alteração significativa, articulada, planejada e operacionalizada por pessoal interno ou externo à organização, que tenha o apoio e supervisão da administração superior, atinja integradamente os componentes de cunho comportamental, estrutural e estratégico.

Ford e Ford (1994)

Van de Ven e Poole (1995) Porras e Robertson (1992)

Woodman (1989)

Araújo (1982)

Quadro 2 - Definições de mudança organizacional

Fonte: Lima e Bressan (2003, p. 23).

Observa-se, dessa forma, que as mudanças organizacionais podem ser entendidas como qualquer modificação, planejada ou não, influenciada por interferências de acontecimentos ocorridos no meio em que a organização está inserida. $\mathrm{O}$ foco da mudança pode estar no indivíduo ou nos componentes da estrutura organizacional.

\subsection{2 - Tipologia da mudança organizacional}

Diversos autores buscaram criar categorias próprias para explicar os diferentes tipos de mudança que podem ocorrer numa organização. Entre eles, estão Nadler e Tushman (1994) e Greenwood e Hinings (1996).

Nadler e Tushman (1994) declaram ser necessário que as organizações reconheçam as necessidades dos diferentes tipos de mudança e saibam como administrá-las. Os autores propõem dois tipos de mudança organizacional - mudança incremental e mudança descontínua. A mudança incremental é caracterizada pelas pequenas mudanças que ocorrem durante períodos de estabilidade, provocando leves oscilações na organização. Esse tipo de 
mudança surge de uma necessidade interna de ajuste da própria organização, voltada para a resolução de problemas e para a busca de uma administração mais eficiente.

O segundo tipo de mudança proposto por Nadler e Tushman (1994), denominada mudança descontínua, ocorre durante períodos de desequilíbrio, provocando fortes oscilações na organização. Trata-se de uma mudança mais profunda, cuja demanda é imposta pelo meio ambiente. A demanda de mudança radical imposta pelo meio ambiente impõe mudanças radicais também à organização.

Greenwood e Hinings (1996) procuraram fornecer uma visão mais completa sobre a compreensão da interpretação organizacional em resposta às pressões contextuais, através do estressamento das políticas de dinâmicas do comportamento intraorganizacional e do envolvimento normativo das organizações com os seus contextos. Eles desenvolveram um modelo de mudança radical para compreender como a mudança ocorre nas organizações, estudando as variações que acontecem em resposta às pressões sofridas, as quais somente podem ser entendidas analisando-se os aspectos das organizações que produzem adoção e difusão ao invés de resistência e inércia.

O objetivo central de Greenwood e Hinings foi explicar a incidência da mudança radical e até que ponto essa mudança é conseguida através de uma forma evolucionária ou revolucionária. Eles ressaltam dois aspectos importantes da mudança: a) a diferença entre mudança radical e convergente e b) a diferença entre mudança evolucionária e revolucionária. A mudança organizacional radical envolveria a quebra de uma orientação existente e a transformação da organização. A mudança convergente seria um ajuste fino da orientação existente. A mudança evolucionária e revolucionária é definida pela escala e pelo ritmo do ajustamento que está sendo feito. Enquanto a evolucionária ocorre devagar e gradualmente, a revolucionária muda rapidamente e afeta virtualmente todas as partes da organização de forma simultânea.

Lima e Bressan (2003) fizeram uma revisão de literatura e sintetizaram as principais tipologias de mudança organizacional. O Quadro 3 mostra as tipologias encontradas pelas autoras: 


\begin{tabular}{|c|c|c|}
\hline Autor & \multicolumn{2}{|c|}{ Tipos de Mudança } \\
\hline $\begin{array}{l}\text { Porras e } \\
\text { Robertson } \\
\text { (1992) }\end{array}$ & $\begin{array}{l}\text { 1a ordem } \\
\text { É uma mudança linear e contínua, que } \\
\text { envolve alterações nas características dos } \\
\text { sistemas, sem causar quebras em } \\
\text { aspectos-chave para a organização. }\end{array}$ & \begin{tabular}{lll} 
& \multicolumn{2}{c}{$\mathbf{2}^{\mathbf{a}}$ ordem } \\
É uma mudança multidimensional, \\
multinível, radical e descontínua, que \\
envolve \\
organizacionais.
\end{tabular} \\
\hline $\begin{array}{l}\text { Nadler et } \\
\text { al (1994) }\end{array}$ & $\begin{array}{l}\text { Incremental/ contínua } \\
\text { Continuidade do padrão existente. Pode } \\
\text { ter dimensões diferentes, mas é realizada } \\
\text { dentro do contexto atual da empresa. }\end{array}$ & $\begin{array}{l}\text { Descontínua } \\
\text { Mudança no padrão existente, que ocorre } \\
\text { em períodos de desequilibro e envolve uma } \\
\text { ou várias reestruturações de características } \\
\text { da empresa. }\end{array}$ \\
\hline $\begin{array}{l}\text { Silva } \\
(1999)\end{array}$ & \begin{tabular}{l}
\multicolumn{4}{c}{ Incremental/ organizacional } \\
Aumento da eficiência e do uso dos \\
recursos, mudança na arquitetura da \\
empresa.
\end{tabular} & $\begin{array}{l}\text { Transformacional/ institucional } \\
\text { Questionamento e mudança da missão, } \\
\text { natureza e objetivo da organização. }\end{array}$ \\
\hline $\begin{array}{l}\text { Weick e Quinn } \\
\quad(1999)\end{array}$ & $\begin{array}{l}\text { Contínua } \\
\text { Mudança constante, cumulativa e } \\
\text { evolutiva. Podem ser pequenos avanços } \\
\text { que ocorrem cotidianamente em toda a } \\
\text { organização, cujo acúmulo pode propiciar } \\
\text { uma mudança significativa na } \\
\text { organização. }\end{array}$ & $\begin{array}{l}\text { Episódica } \\
\text { Mudança pouco freqüente, descontínua e } \\
\text { intencional, que ocorre durante períodos de } \\
\text { divergência, quando as empresas saem de } \\
\text { sua condição de equilíbrio. }\end{array}$ \\
\hline $\begin{array}{l}\text { Robbins } \\
\text { (1999) }\end{array}$ & \begin{tabular}{l}
\multicolumn{1}{c}{$\mathbf{1}^{\mathbf{a}}$ ordem } \\
Mudança linear e contínua. Não implica \\
mudanças fundamentais nas \\
pressuposições dos funcionários sobre o \\
ambiente e sobre aspectos que podem \\
causar melhorias na empresa.
\end{tabular} & $\begin{array}{l}\text { 2 } \mathbf{2}^{\mathbf{a}} \text { ordem } \\
\text { Mudança multidimensional, multinível, } \\
\text { descontínua e radical, que envolve } \\
\text { reenquadramento de pressupostos sobre a } \\
\text { empresa e o ambiente em que ela se insere. }\end{array}$ \\
\hline
\end{tabular}

Quadro 3 - Tipologias da Mudança

Fonte: Lima e Bressan (2003)

Observa-se que, assim como é grande o número de definições sobre mudança organizacional presente na literatura, há também várias tipologias propostas, o que reforça a característica de complexidade que cerca o fenômeno.

\section{3 - Mudança organizacional e universidade corporativa}

São poucos os estudos a respeito da mudança causada pela implantação de universidade corporativa, mas vários autores afirmam que ela pode ser caracterizada como sendo planejada e contínua.

Segundo Porras e Silvers (1991 apud SILVA, 2006) esse tipo de mudança é planejada porque a organização precisa elaborar um plano para que a implantação ocorra e, também, necessita de uma boa definição de modelo de universidade corporativa.

A mudança também é contínua, pois na visão de Weick e Quinn (1999 apud SILVA, 2006) ela possui características de uma mudança constante, cumulativa e evolutiva. Segundo esses autores, são essas as principais características das universidades corporativas, pois elas propõem que o aprendizado seja continuo e, ao mesmo tempo, cumulativo e, principalmente 
evolutivo já que é o maior responsável pelas mudanças organizacionais que a organização planeja alcançar.

Na visão de Fresina (1997 apud SILVA, 2006), as organizações precisam que suas práticas, sistemas, políticas, estratégias e até valores subjacentes sejam ajustados, ou seja, que sofram alterações nas estruturas e para isso, utilizam suas universidades corporativas uma vez que sua principal missão é auxiliar a organização a gerenciar as mudanças. Esse mesmo autor afirma que as universidades corporativas podem ser responsáveis pela direção e modelagem das mudanças organizacionais que devem ser realizadas, uma vez que são usadas pelos líderes como força motriz para adaptar as direções empresariais futuras através de programas e iniciativas de mudanças que objetivam a exploração de novos contextos e alternativas para a organização.

Eboli (2004) realizou um estudo de caráter exploratório, com análise predominantemente qualitativa, isto é, através de pesquisa de campo usando técnica de entrevista semi-estruturada com vinte e um responsáveis pelo projeto de universidade corporativa em organizações brasileiras de vários setores produtivos. A partir de um quadro referencial teórico a respeito dos princípios de sucesso que norteiam esses projetos, as autoras procuraram identificar princípios e práticas utilizadas pelas instituições estudadas sobre concepção e implantação de seus sistemas de Educação Corporativa. A seguir são apresentados os relatos das vinte e uma pessoas pesquisadas, em relação a mudanças ocorridas no ambiente organizacional, retirados do citado estudo:

- Aumento da diferenciação pela qualificação das pessoas;

- Aumento do comprometimento e envolvimento da alta cúpula;

- Alinhamento do modelo de gestão de pessoas às estratégias de negócio;

- Implantação de um modelo de gestão de pessoas por competências;

- Concepção de programas educacionais alinhados às estratégias do negócio;

- Aumento da disseminação da cultura empresarial;

- Aumento da responsabilização de líderes e gestores pelo processo de aprendizagem;

- Adoção de uma educação "inclusiva”, contemplando público interno e externo;

- Implantação de um modelo de gestão do conhecimento;

- Implantação de projetos virtuais de educação - aprendizagem mediada pela tecnologia;

- Implantação de múltiplas formas e processos de aprendizagem que favorecem a "aprendizagem a qualquer hora e em qualquer lugar"; 
- Obtenção da sinergia entre programas sociais e projetos sociais;

- Criação de um ambiente de trabalho que estimulem a geração de novos conhecimentos e novas conexões de conhecimentos já existentes;

- Utilização de uma forma intensiva e inteligente de tecnologia aplicada à gestão do conhecimento, transformando-a numa prática social saudável e moderna que permita unir universo técnico e cultural;

- Ampliação da rede de relacionamentos e estruturação de processos que propiciem o compartilhamento de conhecimentos e a troca de experiências tanto com o público interno quanto com o externo;

- Estruturação de processos que viabilizem a transformação de conhecimento tácito em conhecimento explícito;

- Melhoria da comunicação interna e externa da organização;

- Ampliação da quantidade e a da qualidade da rede de relacionamentos com toda a cadeia de agregação de valor: fornecedores, distribuidores, clientes, comunidades;

- Aumento da preocupação e do compromisso da empresa com a cidadania e responsabilidade social por meio da implantação de programas educacionais específicos para este fim.

Queiroz, Fachin e Santana (2004), diferentemente de Éboli, realizaram um estudo de caso com entrevistas semi-estruturadas com dezesseis pessoas e mais aplicação de questionários em 54 sujeitos, além de uma análise documental, na universidade corporativa do grupo ALCAR. O foco da pesquisa era analisar se o modelo de universidade corporativa implantado pela empresa representava na prática um progresso em relação á antigo área de T\&D - Treinamento e Desenvolvimento. Os sujeitos do estudo deveriam falar sobre mudanças ocorridas na estratégia de educação, a apartir da implantação da universidade corporativa e, segundo eles:

- Houve uma mudança na proposição de treinamentos, uma vez que a empresa passou a oferecer treinamentos mais direcionados às reais necessidades da organização;

- Maior conscientização da necessidade de aprendizado diversificado e constante;

- Maior integração e troca de experiências entre seus usuários;

- A educação passou a ser tratada como um negócio economicamente autosustentado pela organização. 
Soares (2004) relata que uma das mudanças organizacionais provocadas pelas universidades corporativas é a inclusão na sua cultura interna de elementos relacionados com a qualidade, gestão de intangíveis, capital, propriedade intelectual e inovação e, afirma ainda, que as universidades corporativas são capazes de ser instrumentos de grande valia na dispersão de uma nova cultura tecnológica com todos valores que a mesma tem.

Nessa mesma linha, Bonilauri (2005) afirma que as universidades corporativas propiciam uma maior vinculação das medidas indiretas com os resultados mais objetivos da empresa, expressos por indicadores de receita, margem e lucro, porque procuram medidas diretas do esforço gasto na educação de seus empregados e impactos destes sobre os resultados, muitas vezes apreciados pela relação custo/benefício. 


\section{CAPÍTULO 2 - ASPECTOS METODOLÓGICOS DA PESQUISA}

Neste Capítulo são descritos os procedimentos metodológicos utilizados na condução da pesquisa para responder ao seguinte problema: "Na percepção dos empregados, a implantação da universidade corporativa provoca mudanças organizacionais?”

\section{1 - Tipo de pesquisa}

São muitas as classificações de pesquisas existentes na literatura de Metodologia Científica. Tomando-se por base a classificação proposta por Vergara (2006), a pesquisa proposta classifica-se quanto aos fins em exploratória e descritiva, pois aborda temas sobre os quais poucas pesquisas foram realizadas, e quanto aos fins pode ser considerada pesquisa de campo, pois será realizada no próprio local onde o fenômeno ocorre. A pesquisa utilizou, também, uma abordagem quantitativa.

\section{2 - Contexto da pesquisa}

A pesquisa foi realizada na empresa "Centrais Elétricas do Norte do Brasil S.A." (Eletronorte). Criada pela Lei 5.824, de 1972, constituída e autorizada a funcionar em 1973, trata-se de empresa de economia mista, com sede no Distrito Federal.

A Eletronorte tem como finalidade principal a realização de estudos, projetos, construção e operação de usinas geradoras e de sistemas de transmissão de energia elétrica, além da comercialização da energia gerada. A Empresa gera e transmite energia na Região Amazônica, nos estados do Acre, Amapá, Amazonas, Maranhão, Mato Grosso, Pará, Rondônia, Roraima e Tocantins. Construiu e opera usinas hidrelétricas (Tucuruí, Balbina na Manaus Energia, Samuel e Coaracy Nunes), parques térmicos e sistemas de transmissão associados.

Por meio do Sistema Interligado Nacional, a Empresa é destaque no cenário brasileiro por sua comercialização de energia abranger todo o território nacional, em seus diferentes segmentos de mercado de energia.

O Quadro 4, apresentado a seguir, descreve a missão, visão e valores da Eletronorte: 


\begin{tabular}{|c|l|}
\hline MISSÃO & $\begin{array}{l}\text { Atuar no negócio de energia elétrica com rentabilidade e responsabilidade socioambiental, } \\
\text { contribuindo para o desenvolvimento do País }\end{array}$ \\
\hline VISÃO & $\begin{array}{l}\text { Com energia e comprometimento, ser uma Empresa sustentável, referencial de excelência } \\
\text { e valorizada pela sociedade }\end{array}$ \\
\hline VALORES & $\begin{array}{l}\text { Excelência na Gestão, Valorização das pessoas, Comprometimento das pessoas, } \\
\text { Aprendizado continuo, Empreendimento, Ética e Transparência. }\end{array}$ \\
\hline
\end{tabular}

Quadro 4 - Missão, Visão e Valores da Eletronorte

Em 2002, a Eletronorte criou a Universidade Corporativa Eletronorte (Ucel). Trata-se de uma entidade educacional que funciona como uma ferramenta estratégica cuja função é ajudar a promover a educação continuada e a gestão do conhecimento por intermédio de ações educativas alinhadas ao planejamento estratégico empresarial e às competências organizacionais e humanas.

A missão da Ucel é "Atuar como agente integrador entre as ações educacionais e os negócios estratégicos da Empresa, promovendo a gestão de pessoas e do conhecimento, conforme preconizado no Plano Estratégico Empresarial”. A Universidade tem como visão "Ser referência em educação corporativa na busca da excelência pela gestão de pessoas e do conhecimento na organização";

A Figura 1 mostra a localização da Ucel no organograma da Eletronorte.

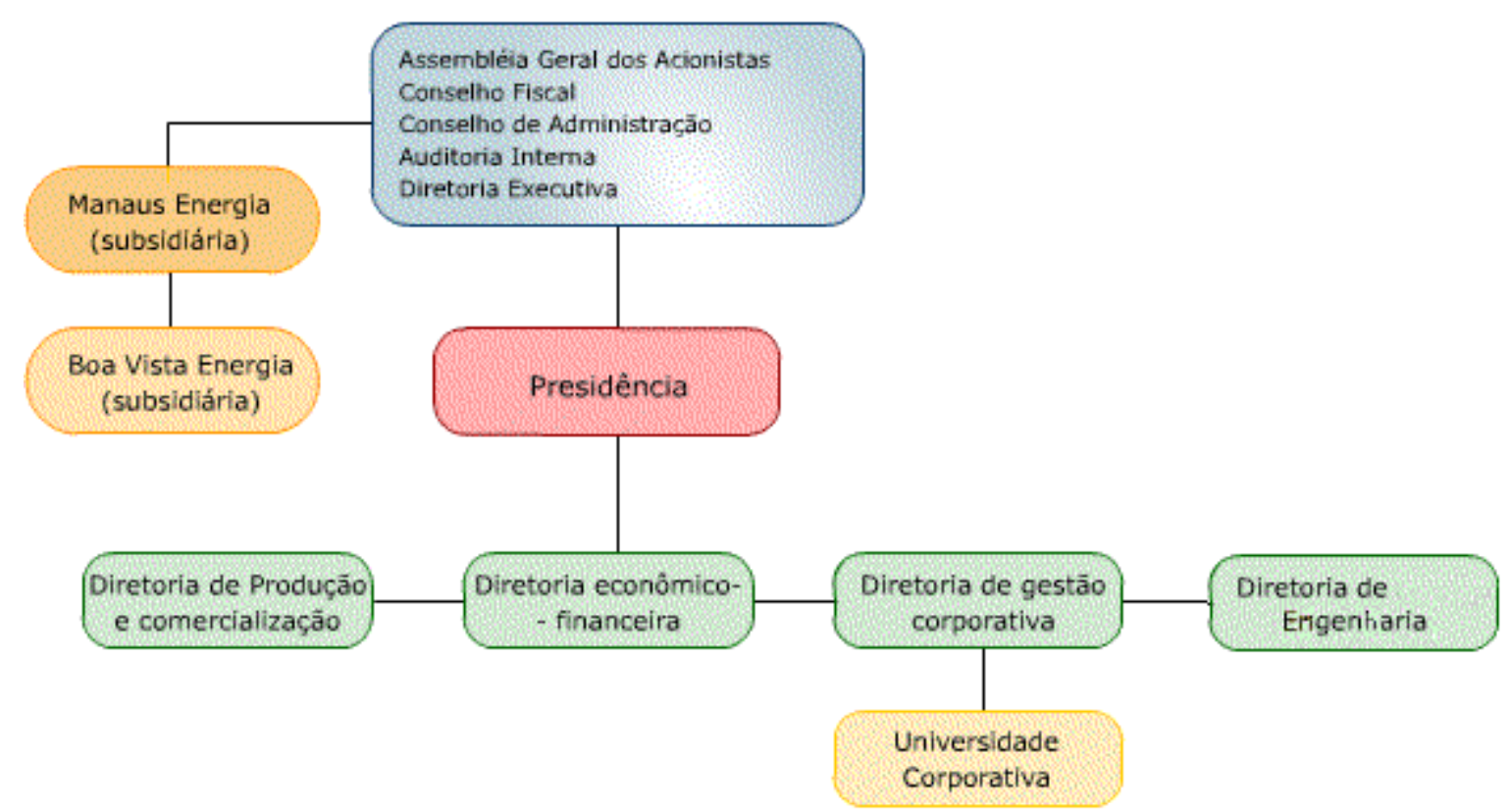

Figura 1 - Localização da Ucel no Organograma da Eletronorte 


\section{3 - Sujeitos da pesquisa}

O critério de seleção dos sujeitos foi o tempo de serviço na Eletronorte. Como a pesquisa tinha por objetivo avaliar a percepção dos empregados com relação às mudanças ocorridas na organização em razão da implantação da universidade, era essencial que os participantes tivessem vivenciado o período que antecedeu a criação da Ucel em 2002.

Dessa forma, a pesquisa abrangeu todas as pessoas que estavam trabalhando na Eletronorte há, no mínimo, seis anos, envolvendo empregados do quadro efetivo, terceirizados e cedidos, lotados na Sede da Empresa em Brasília e nas Regionais. De acordo com os dados levantados na Empresa, à época da aplicação da pesquisa, havia um total de 2.312 empregados do quadro efetivo e cedidos. Em razão do tipo de registros mantidos pela Eletronorte, não foi possível obter o quantitativo de terceirizados que atendiam a esse critério de tempo de serviço.

O questionário foi respondido por 270 pessoas, sendo esse o quantitativo final de sujeitos considerado na análise dos dados da pesquisa. O perfil desses respondentes será apresentado nos próximos segmentos.

\subsubsection{Gênero}

Tabela 1 - Gênero dos Sujeitos

\begin{tabular}{|l|c|c|}
\hline \multicolumn{1}{|c|}{ Gênero } & f & \% \\
\hline Masculino & $\mathbf{1 9 6}$ & $\mathbf{7 2 , 6}$ \\
\hline Feminino & 73 & 27,0 \\
\hline Dado ausente & 1 & 0,4 \\
\hline Total & 270 & 100,0 \\
\hline
\end{tabular}

Os resultados apresentados na Tabela 1 mostram que a maior parte dos respondentes $(72,6 \%)$ é do sexo masculino. Apenas um participante deixou de informar esse dado na pesquisa. 


\subsubsection{Escolaridade}

Tabela 2 - Escolaridade dos Sujeitos

\begin{tabular}{|c|c|c|}
\hline Nível de Escolaridade & $\mathbf{f}$ & $\%$ \\
\hline Ensino Fundamental & 1 & 0,4 \\
\hline Ensino Médio Incompleto & 2 & 0,7 \\
\hline Ensino Médio Completo & 40 & 14,8 \\
\hline Superior Incompleto & 36 & 13,3 \\
\hline Superior Completo & 95 & 35,2 \\
\hline Especialização Incompleta & 11 & 4,1 \\
\hline Especialização Completa & 59 & 21,9 \\
\hline Mestrado Incompleto & 9 & 3,3 \\
\hline Mestrado Completo & 15 & 5,6 \\
\hline Doutorado Incompleto & 2 & 0,7 \\
\hline Doutorado Completo & - & - \\
\hline Total & 270 & 100,0 \\
\hline
\end{tabular}

Os dados referentes a Tabela 2 mostram que o maior percentual de participantes da pesquisa $(35,2 \%)$ pertence a empregados com apenas o nível superior completo. Entretanto, se somados os percentuais dos empregados que estão cursando ou concluíram uma pósgraduação, esse valor sobe para $70,8 \%$, sinalizando que os respondentes da pesquisa possuíam um bom nível de escolaridade. 


\subsubsection{Faixa Etária}

Tabela 3 - Faixa Etária dos Sujeitos

\begin{tabular}{|c|c|c|}
\hline \multicolumn{1}{|c|}{ Faixa Etária } & $\mathrm{f}$ & $\%$ \\
\hline Até 30 anos & 11 & 4,1 \\
\hline 31 a 40 anos & 20 & 7,4 \\
\hline 41 a 50 anos & 126 & 46,7 \\
\hline Acima de 51 anos & 113 & 41,9 \\
\hline Total & 270 & 100,0 \\
\hline
\end{tabular}

Com relação à faixa etária, observa-se que o maior percentual de participantes da pesquisa $(46,7 \%)$ possui idade entre 41 a 50 anos. O menor percentual de respondentes $(4,1 \%)$ refere-se aos empregados com até 30 anos de idade. Esse baixo percentual de empregados com uma faixa etária mais jovem provavelmente se deve ao fato do critério adotado para a seleção dos sujeitos - tempo mínimo de serviço de seis anos. Há cerca de dois anos, a Eletronorte começou o processo de renovação do seu quadro de pessoal, com a realização de concurso público para a entrada de novos empregados.

\subsubsection{Tempo de Serviço}

Tabela 4 - Tempo de Serviço na Eletronorte

\begin{tabular}{|l|c|c|}
\hline \multicolumn{1}{|c|}{ Tempo de Serviço } & f & \% \\
\hline 6 a 10 anos & 26 & 9,6 \\
\hline 11 a 15 anos & 4 & 1,5 \\
\hline 16 a 20 anos & 71 & 26,3 \\
\hline Mais de 21 anos & $\mathbf{1 6 9}$ & $\mathbf{6 2 , 6}$ \\
\hline Total & 270 & 100,0 \\
\hline
\end{tabular}


Empregados com mais de 21 anos de tempo de serviço formaram mais da metade dos respondentes $(62,6 \%)$. Esse dado contribui positivamente para os resultados encontrados na pesquisa, uma vez que se trata de pessoas que vivenciaram por um tempo maior o período que antecedeu a implantação da universidade corporativa da Empresa.

\subsubsection{Categoria Funcional}

Tabela 5 - Categoria Funcional

\begin{tabular}{|l|c|c|}
\hline \multicolumn{1}{|c|}{ Categoria Funcional } & $\mathbf{f}$ & $\mathbf{\%}$ \\
\hline Empregado & $\mathbf{2 6 0}$ & $\mathbf{9 6 , 3}$ \\
\hline Cedido & 1 & 0,4 \\
\hline Prestador (a) de Serviço Terceirizado & 9 & 3,3 \\
\hline Total & 270 & 100,0 \\
\hline
\end{tabular}

Os dados da Tabela 5 mostram que quase a totalidade dos participantes da pesquisa $(96,3 \%)$ pertence ao quadro de empregados efetivos da Eletronorte. Esse resultado reflete a atual política da Empresa e do serviço público como um todo, voltada para a substituição gradativa dos prestadores por empregados concursados.

\subsubsection{Lotação}

Os resultados referentes à lotação dos participantes da pesquisa são mostrados na Tabela 6, apresentada a seguir. 
Tabela 6 - Lotação

\begin{tabular}{|c|c|c|}
\hline Lotação & f & $\%$ \\
\hline SEDE & 111 & 41,1 \\
\hline CAC & 16 & 5,9 \\
\hline CAP & 12 & 4,4 \\
\hline CMA & 18 & 6,7 \\
\hline CMT & 9 & 3,3 \\
\hline $\mathrm{CPA}^{*}$ & 39 & 14,4 \\
\hline CRD & 11 & 4,1 \\
\hline CRR & 6 & 2,2 \\
\hline CTC & 19 & 7,0 \\
\hline СТО & 14 & 5,2 \\
\hline EAC & 2 & 0,7 \\
\hline EMA & 4 & 1,5 \\
\hline EPA & 3 & 1,1 \\
\hline ERO & 2 & 0,7 \\
\hline ETC & 2 & 0,7 \\
\hline GRP & 2 & 0,7 \\
\hline Total & 270 & 100,0 \\
\hline
\end{tabular}

*No CPA estão, também, os respondentes lotados no CCT.

Os dados da Tabela 6 mostram que a Sede foi responsável por 41,1\% de participação na pesquisa. Nota-se, contudo, que, se somados os outros percentuais, a participação das regionais também foi bastante expressiva, atingindo um total de 58,9\%. 


\subsubsection{Função}

Tabela 7 - Função dos Participantes da Pesquisa

\begin{tabular}{|c|c|c|}
\hline Função & $\mathbf{f}$ & $\%$ \\
\hline Assessor / Assistente de Diretoria & 12 & 4,4 \\
\hline Superintendente & 5 & 1,9 \\
\hline Gerente & 32 & 11,9 \\
\hline Analista & 45 & 16,7 \\
\hline Técnica & 176 & 65,2 \\
\hline Total & 270 & 100,0 \\
\hline
\end{tabular}

Observa-se, na Tabela 7 , que o maior percentual de respondentes $(65,2 \%)$ está na função "Técnica", que abrange ocupantes de nível fundamental ou médio. Esse resultado, aparentemente discrepante daquele encontrado na Tabela 2 cujo nível de Escolaridade era superior completo, talvez possa ser explicado pela publicação da Constituição da República Federativa do Brasil de 1988, artigo n ${ }^{\circ} 37$, que estabelece as normas para ingressos em cargos públicos. Assim, muitos servidores que entraram como nível médio no passado, hoje podem ter adquirido uma melhor formação acadêmica, mas isso não os tornam elegíveis para a ocupação automática de um cargo de nível superior.

\section{4 - Instrumento}

Para identificar quais as mudanças organizacionais ocorridas pela implantação da Universidade Corporativa, na percepção dos empregados, foi utilizada a "Escala de Percepção de Mudança Organizacional Causada pela Introdução de Universidade Corporativa”, construída e validada por Silva (2006). Esse instrumento é composto por itens para serem respondidos com base em uma escala do tipo "Likert", de cinco pontos, variando de "discordo totalmente" até "concordo totalmente". Cópia do instrumento encontra-se no Anexo "B". 


\section{5 - Coleta de dados}

Foi enviado um e-mail institucional para todos os empregados da Eletronorte solicitando que respondessem a pesquisa apenas os que tinham, no mínimo, seis anos de serviço na Empresa. O e-mail continha um link para a versão eletrônica do instrumento que ficou em uma base de dados especialmente preparada para receber as informações coletadas utilizado o Software Lime Survey.

Na página da Universidade Corporativa da Eletronorte também estava disponível uma janela de pop-up com um link da pesquisa para que os que visitassem o site pudessem ter acesso e preencher o questionário.

A pesquisa ficou disponível durante uma semana, no período de 14 a 21 de outubro de 2008. No dia 20 de outubro foi verificado que tinha, aproximadamente, 170 questionários respondidos. Com o objetivo de estimular um número maior de respostas, foi passado um novo e-mail, dessa vez para os coordenadores e gestores das Regionais, solicitando uma maior cooperação dos empregados.

\section{6 - Análise dos dados}

Com os dados da pesquisa, após serem transferidos automaticamente do Lime Survey para a planilha do Statistical Package for Social Sciences (SPSS), foram feitas as análises estatísticas. 


\section{CAPÍTULO 3 - APRESENTAÇÃO E DISCUSSÃO DOS RESULTADOS}

Este Capítulo está estruturado em duas seções. A primeira apresenta e discute os resultados encontrados com a realização da pesquisa. A segunda fornece alguns subsídios à empresa pesquisada, com base nesses resultados.

\section{1 - A Ucel e as mudanças organizacionais na Eletronorte}

No subitem 2.4 do capítulo anterior, foi informado que a pesquisa utilizaria um instrumento construído e validado por Silva (2006), para investigar a percepção dos empregados sobre possíveis mudanças organizacionais ocorridas em função da implantação da Universidade Corporativa Eletronorte (Ucel).

O instrumento de Silva (2006) possui 27 itens distribuídos em quatro fatores: 1) foco no modelo de gestão por competências; 2) aumento da visibilidade interna e externa da organização; 3) estímulo à educação continuada; 4) estabelecimento de parcerias entre a organização e instituições de ensino:

- Fator 1 - Foco no modelo de gestão por competências - Retrata a adoção de um modelo de gestão baseada em competências, que possibilita à organização identificar e desenvolver competências internas e externas necessárias à manutenção e ao destaque em que está inserida. O fator é formado por 11 itens.

- Fator 2 - Aumento da visibilidade interna e externa da organização Refere-se a uma maior visibilidade da organização, em decorrência da implantação da universidade corporativa, pela oferta às empresas parceiras e comunidades locais, de treinamento e outras ações de aprendizagem. É composto por 8 itens.

- Fator 3 - Estímulo à educação continuada - Agrupa 5 itens que buscam expressar como, a partir de ações educacionais, as universidades corporativas contribuem para ampliar as oportunidades de aprendizagem nas organizações.

- Fator 4 - Estabelecimento de parcerias entre a organização e instituições de ensino - $\mathrm{O}$ fator, composto por três itens, caracteriza o surgimento de novas práticas ou idéias nas organizações em função do 
estabelecimento de parcerias com o meio acadêmico, proporcionadas pela implantação de uma universidade corporativa.

\subsection{1 - Consistência interna dos itens do instrumento}

Primeiramente, foi feita uma análise de confiabilidade para verificar a consistência interna dos itens que formavam o instrumento, comparando-a com os resultados encontrados originalmente por Silva (2006). A Tabela 8 mostra a comparação dos índices de confiabilidade (Alfa de Cronbach) encontrados nas duas pesquisas:

Tabela 8 - Consistência interna dos fatores: comparação entre duas aplicações do instrumento de pesquisa

\begin{tabular}{|l|c|c|}
\hline \multicolumn{1}{|c|}{ Fator } & \multicolumn{2}{|c|}{ Universidade Corporativa } \\
\hline F1 - Foco no modelo de gestão por competências & UniSESI & Ucel \\
\hline F2 - Aumento da visibilidade interna e externa da organização & $\alpha=0,91$ & $\boldsymbol{\alpha}=\mathbf{0 , 9 5}$ \\
\hline F3 - Estimulo à educação continuada & $\alpha=0,85$ & $\boldsymbol{\alpha}=\mathbf{0 , 9 3}$ \\
\hline F4 - Estabelecimento de parcerias entre a organização e instituições de ensino & $\alpha=0,74$ & $\boldsymbol{\alpha}=\mathbf{0 , 8 6}$ \\
\hline
\end{tabular}

Uma análise dos dados da Tabela 8 mostra que os índices de confiabilidade encontrados na aplicação do instrumento na Ucel foram superiores aos obtidos por Silva (2006) na UniSESI, indicando que o instrumento possui uma boa estrutura empírica.

Os valores mais elevados encontrados com a aplicação do instrumento na Ucel talvez possam ser explicados por algumas razões. Uma delas pode ser a boa relação obtida entre o número de sujeitos e o número de itens do instrumento. Como foram 270 sujeitos e o instrumento tinha 27 itens, a razão de casos por variável foi de 10:1, considerada uma amostra adequada conforme a literatura da área. Outra razão pode estar atrelada ao tempo de existência das duas universidades corporativas. À época da aplicação do instrumento por Silva, a UniSESI tinha, aproximadamente, três anos, enquanto a Ucel, no período de realização da presente pesquisa contabilizava seis anos de existência. 


\subsection{2 - Média e desvio padrão dos fatores do instrumento}

Após a realização do teste de confiabilidade dos itens do instrumento, foram calculados a média e o desvio padrão de cada um dos quatro fatores. Os resultados estão descritos na Tabela 9:

Tabela 9 - Média e Desvio padrão dos Fatores do Instrumento

\begin{tabular}{|l|c|c|}
\hline \multicolumn{1}{|c|}{ Fator } & Média & Desvio padrão \\
\hline Foco no modelo de gestão por competências & 3,88 & 0,88 \\
\hline Aumento da visibilidade interna e externa da organização & 3,78 & 0,87 \\
\hline Estímulo à educação continuada & $\mathbf{4 , 1 9}$ & $\mathbf{0 , 8 4}$ \\
\hline Estabelecimento de parcerias entre a organização e instituições de ensino & $\mathbf{4 , 0 6}$ & $\mathbf{0 , 8 7}$ \\
\hline
\end{tabular}

Os resultados apresentados na Tabela 9 demonstram que dois fatores ficaram com médias mais altas, entre os pontos 4 "concordo pouco" e 5 "concordo totalmente". Esses fatores foram "Estímulo à educação continuada", média 4,19, e "Estabelecimento de parcerias entre a organização e instituições de ensino", com média de 4,06. Os desvios padrões baixos, 0,84 e 0,87 , respectivamente, sinalizam que houve alta concordância entre os participantes da pesquisa com relação às afirmações feitas nesses itens do instrumento. Na percepção dos respondentes, a partir da implantação da Ucel, houve maior oferta de oportunidades educacionais oferecidas pela Eletronorte, bem como estreitamento das relações entre a empresa e as instituições de ensino.

Continuando a análise dos dados da Tabela 9, observa-se que os outros dois fatores que compunham o instrumento -"Foco no modelo de gestão por competências" e "Aumento da visibilidade interna e externa da organização" - ficaram com médias mais baixas, situadas entre os pontos 3 "em dúvida" e 4 "concordo pouco". Nesses fatores, os desvios padrões baixos também apontam alta concordância entre as respostas dos sujeitos.

A Tabela 10, apresentada a seguir, mostra a distribuição das médias e desvios padrões dos itens que formavam os dois fatores que obtiveram as médias mais altas - "Estímulo à Educação Continuada" e "Estabelecimento de Parcerias entre a Organização e Instituições de Ensino": 
Tabela 10 - Média e Desvio padrão dos Itens dos Fatores 3 e 4

\begin{tabular}{|c|c|c|c|}
\hline Fator & Item & Média & $\begin{array}{l}\text { Desvio } \\
\text { Padrão }\end{array}$ \\
\hline \multirow{5}{*}{ 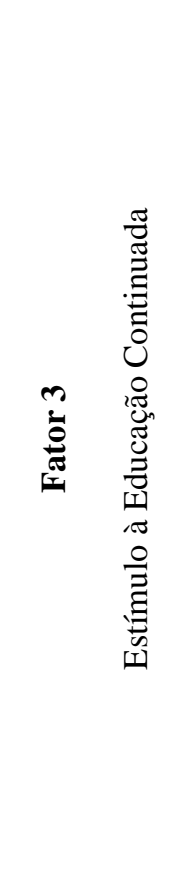 } & $\begin{array}{l}\text { Ampliaram-se as oportunidades de aprendizagem na Eletronorte } \\
\text { reforçando a idéia de educação permanente. }\end{array}$ & 4,29 & 1,01 \\
\hline & $\begin{array}{l}\text { Facilitou-se o aprendizado contínuo dos empregados na Eletronorte } \\
\text { reforçando a idéia de educação permanente. }\end{array}$ & 4,21 & 1,02 \\
\hline & $\begin{array}{l}\text { Ampliou-se o acesso aos cursos a distância, com utilização do espaço } \\
\text { web contribuindo para o contínuo processo de educação dos } \\
\text { empregados. }\end{array}$ & 4,52 & 0,84 \\
\hline & $\begin{array}{l}\text { Expandiu-se a cultura de aprendizagem ao longo da vida a partir da } \\
\text { disseminação do conhecimento produzido por indivíduos e grupos na } \\
\text { Eletronorte. }\end{array}$ & 3,93 & 0,94 \\
\hline & $\begin{array}{l}\text { Houve uma maior contribuição para a aprendizagem organizacional a } \\
\text { partir da disseminação do conhecimento produzido por indivíduos e } \\
\text { grupos na Eletronorte. }\end{array}$ & 3,97 & 1,04 \\
\hline \multirow{3}{*}{ 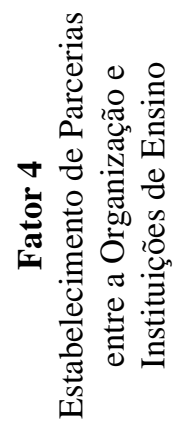 } & $\begin{array}{l}\text { Houve uma maior aproximação entre a Eletronorte e instituições de } \\
\text { ensino. }\end{array}$ & 4,06 & 0,99 \\
\hline & $\begin{array}{l}\text { Ampliou-se a interação com instituições de ensino contribuindo para } \\
\text { as ações educacionais desenvolvidas na Eletronorte. }\end{array}$ & 4,16 & 0,96 \\
\hline & $\begin{array}{l}\text { A interação com culturas diferentes (Eletronorte versus instituições } \\
\text { de ensino superior) passou a ser mais constante. }\end{array}$ & 3,96 & 1,00 \\
\hline
\end{tabular}

A Tabela 10 mostra que no Fator 3 -"Estímulo à Educação Continuada" - o item que obteve média mais alta, 4,52, foi "ampliou-se o acesso aos cursos a distância, com utilização do espaço web contribuindo para o contínuo processo de educação dos empregados". O desvio padrão baixo, 0,84, mostrou que houve grande concordância entre as respostas dadas pelos participantes da pesquisa.

No Fator 4 - "Estabelecimento de Parcerias entre a Organização e Instituições de Ensino" - o item "ampliou-se a interação com instituições de ensino contribuindo para as ações educacionais desenvolvidas na Eletronorte" obteve a maior média $(4,16)$ e o desvio padrão mais baixo $(0,96)$. 


\subsection{3 - Estudo de correlações}

A partir dos dados obtidos com a pesquisa, buscou-se investigar, também, possíveis associações existentes entre as variáveis demográficas - gênero, escolaridade, faixa etária, tempo de serviço, categoria funcional, lotação e função - e os quatro fatores do instrumento. A Tabela 11 mostra os resultados das correlações encontradas:

Tabela 11 - Correlação entre as Variáveis Demográficas (VI’s) e os Fatores do Instrumento (VD’s)

\begin{tabular}{|c|c|c|c|c|c|c|c|c|}
\hline \multirow{2}{*}{ VI's } & \multicolumn{2}{|c|}{ Fator 1} & \multicolumn{2}{|c|}{ Fator 2} & \multicolumn{2}{|c|}{ Fator 3} & \multicolumn{2}{|c|}{ Fator 4} \\
\hline & $\mathbf{r}$ & $\mathbf{p}$ & $\mathbf{r}$ & p & $\mathbf{r}$ & p & $\mathbf{r}$ & $\mathbf{p}$ \\
\hline Gênero & 0,041 & $0,125^{*}$ & 0,030 & $0,132 *$ & & & & \\
\hline Escolaridade & & & 0,002 & $-0,190 * *$ & & & & \\
\hline Lotação & 0,005 & $0,171^{* *}$ & 0,006 & $0,167 * *$ & 0,016 & $0,147 *$ & 0,033 & $0,130 *$ \\
\hline
\end{tabular}

Observa-se na Tabela 11 que somente três variáveis demográficas - gênero, escolaridade e lotação - apresentaram correlações significativas com, pelo menos, um dos quatro fatores do instrumento:

- Gênero - Foi observada correlação positiva entre essa variável e os Fatores 1 e 2 do instrumento, sinalizando que os homens percebem mais as mudanças relacionadas ao "foco no modelo de gestão por competências" e ao "aumento da visibilidade interna e externa da organização”.

- Escolaridade - Houve correlação negativa entre essa variável e o Fator 2 "aumento da visibilidade interna e externa da organização", apontando que os respondentes com maior nível de escolaridade foram os que mais perceberam a mudança associada a esse fator, causada pela implantação da Ucel.

- Lotação - Essa variável mostrou associação com todos os quatro fatores do instrumento. O sinal positivo indicou que os respondentes lotados na sede perceberam mais as mudanças do que aqueles lotados nas regionais da Empresa. 


\section{2 - Subsídios gerados pelos resultados da Pesquisa}

A análise dos dados da pesquisa, feita no subitem anterior, permite fornecer alguns subsídios à Eletronorte sobre a percepção dos seus empregados em relação às mudanças organizacionais decorrentes da implantação da sua universidade corporativa. Tomando-se por base os quatro fatores que compõem o instrumento de pesquisa, os resultados permitem as seguintes observações:

\section{Fator 1 - Foco no modelo de gestão por competências}

O Fator 1 recebeu a segunda média mais baixa, 3,88, indicando que os respondentes ficaram em dúvida ou concordaram pouco com as afirmativas feitas nos itens que o compunham. O resultado pode estar indicando que, na percepção dos participantes da pesquisa, não está muito claro o fato de que a implantação da Ucel tenha modificado as práticas da Eletronorte com relação ao foco no modelo de gestão por competências.

Esse resultado é compatível com a realidade atual da empresa, uma vez que o sistema de carreiras por habilidades e competências ainda não se encontra totalmente implantado. A sua implantação poderia fortalecer o modelo de universidade corporativa adotado pela empresa.

\section{Fator 2 - Aumento da visibilidade interna e externa da organização}

Esse Fator refere-se a uma maior visibilidade da organização, em decorrência da implantação da universidade corporativa, pela oferta às empresas parceiras e comunidades locais, de treinamento e outras ações de aprendizagem. Dentre os quatro fatores foi o que recebeu a média mais baixa, 3,78, indicando que os participantes da pesquisa ficaram em dúvida ou concordaram pouco com as afirmações feitas nos itens do instrumento.

Esse resultado pode estar demonstrando que a Eletronorte precisa aumentar a oferta de ações educacionais às empresas parceiras e as comunidades onde atua, para melhorar a visibilidade da organização.

\section{Fator 3 - Estímulo à educação continuada}

Esse Fator agrupa itens que buscam expressar como, a partir de ações educacionais, as universidades corporativas contribuem para ampliar as oportunidades de aprendizagem nas 
organizações. No caso da pesquisa realizada na Eletronorte, foi o Fator que teve a média mais alta, 4,19, indicando que os respondentes escolheram entre os pontos 4 "concordo pouco" e 5 "concordo totalmente".

Esse resultado demonstra que é forte, entre os participantes da pesquisa, a percepção de que a implantação da Ucel constituiu-se em estímulo à educação continuada dentro da Eletronorte. Foi observado que, dentro desse Fator, o item "ampliou-se o acesso aos cursos a distância, com utilização do espaço web, contribuindo para o contínuo processo de educação dos empregados" obteve a maior média, 4,52.

A média alta recebida por esse item pode estar associada ao fato de que, em 2001, a Eletronorte preocupou-se em criar o Programa Eletronorte de Educação a Distância EDUCAR, como um dos alicerces para a implantação da universidade corporativa ocorrida um ano depois. Desde então, a empresa tem se destacado na oferta de cursos na modalidade a distância por meio de diversas mídias como TV Educativa, Videoconferência, Web e outras. Os resultados da presente pesquisa apontam que esse esforço da empresa é bastante visível na percepção dos empregados, significando que a Eletronorte deve continuar com sua política de diversificação das metodologias de ensino-aprendizagem utilizadas.

\section{Fator 4 - Estabelecimento de parcerias entre a organização e instituições de ensino}

Esse Fator obteve a segunda maior média, 4,06. Ele caracteriza o surgimento de novas práticas ou idéias nas organizações em função do estabelecimento de parcerias com o meio acadêmico, proporcionadas pela implantação de uma universidade corporativa.

$\mathrm{O}$ resultado encontrado sinaliza que os participantes da pesquisa percebem que houve uma mudança com relação ao estreitamento das parcerias com instituições de ensino a partir da implantação da Ucel. Prova disso é que, dentro desse Fator, o item "ampliou-se a interação com instituições de ensino contribuindo para as ações educacionais desenvolvidas na Eletronorte" foi o que recebeu a maior média $(4,16)$ por parte dos respondentes.

Para a Eletronorte, o resultado indica que esse tipo de parceria é bastante visível na percepção dos empregados, o que pode ser um aspecto organizacional positivo. 


\section{CONCLUSÃO}

Este trabalho buscou responder ao seguinte problema de pesquisa: "Na percepção dos empregados, a implantação de uma universidade corporativa provoca mudanças organizacionais?" Para respondê-lo foram estabelecidos os seguintes objetivos:

\section{Geral}

- Estudar as mudanças organizacionais decorrentes da implantação de uma universidade corporativa.

\section{Específicos}

- Investigar, na percepção dos empregados de uma empresa pública do setor elétrico brasileiro, se ocorreram mudanças organizacionais com a implantação da universidade corporativa.

- Fornecer subsídios à organização pesquisada sobre o processo de consolidação da sua universidade corporativa.

A pesquisa foi conduzida na empresa "Centrais Elétricas do Norte do Brasil S/A Eletronorte". A partir da aplicação do instrumento "Escala de Percepção de Mudança Organizacional Causada pela Introdução de Universidade Corporativa”, construído e validado por Silva (2006), pode-se destacar os seguintes resultados:

a) Houve uma maior percepção dos participantes da pesquisa com relação a dois fatores que representariam mudanças organizacionais causadas pela introdução da Ucel. Esses fatores foram: "Estímulo à educação continuada" e "Estabelecimento de parcerias entre a organização e instituições de ensino". Esses dois fatores obtiveram médias acima do ponto 4 da escala, mostrando que os respondentes escolheram entre "concordo pouco" e "concordo totalmente" com as afirmativas.

b) Dentre os quatro fatores do instrumento, os que obtiveram médias mais baixas foram "Foco no modelo de gestão por competências" e "Aumento da visibilidade interna e externa da organização". As médias para esses 
dois fatores ficaram entre o ponto 3 "em dúvida" e 4 "concordo pouco" com as afirmativas feitas nos itens do instrumento.

Para a empresa pesquisada, os subsídios fornecidos por esses resultados indicam alguns aspectos relevantes, por exemplo:

- No caso do Fator 1 - "Foco no modelo de gestão por competências" observa-se que a implantação do sistema de carreiras por habilidades e competências fortaleceria o modelo de universidade corporativa adotado pela empresa.

- Com referência ao Fator 2 - "Aumento da visibilidade interna e externa da organização" - parece ser recomendável que a Eletronorte aumente a oferta de ações educacionais às empresas parceiras e as comunidades onde atua, para melhorar a visibilidade da organização.

- No Fator 3 - "Estímulo à educação continuada" - foi observado que é percebido pelos empregados o empenho da empresa em ofertar ações educacionais por meio de diversas metodologias de ensino-aprendizagem.

- O Fator 4 - "Estabelecimento de parcerias entre a organização e instituições de ensino" - também é uma ação da Eletronorte/Ucel que foi percebido positivamente pelos participantes da pesquisa.

Uma comparação com a pesquisa feita por Silva (2006), quando da aplicação do seu instrumento no SESI, mostra que, no caso da Eletronorte, os resultados foram mais otimistas com relação às mudanças organizacionais causadas pela introdução de uma universidade corporativa:

- Na pesquisa feita por Silva, apenas o Fator 3 - "Estímulo a educação continuada" - ficou com média acima de 4. Na Eletronorte, além do Fator 3, também o Fator 4 - "Estabelecimento de parcerias entre a organização e instituições de ensino" - ficou com média entre os pontos 4 e 5 da escala de concordância do instrumento.

- Em todos os quatro fatores, as médias obtidas com a pesquisa feita na Eletronorte foram superiores às encontradas no SESI. Em ambas as pesquisas, os desvios padrões encontrados foram baixos, mostrando ter havido alta concordância dos respondentes com relação aos itens do instrumento. 
- No caso do SESI, não foram encontradas correlações significativas entre os quatro fatores e as variáveis demográficas dos respondentes. Na Eletronorte, dentre as sete variáveis demográficas, três apresentaram correlações significativas com pelo menos um dos quatro fatores.

A diferença entre os resultados encontrados nas duas organizações talvez possa ser explicada pelo tempo de vida que cada universidade corporativa possuía a época da realização das pesquisas. Enquanto a UniSESI tinha pouco tempo de existência, cerca de três anos, a Ucel contabilizava seis anos de vida.

Ressalta-se a boa consistência interna observada nos itens da "Escala de Percepção de Mudança Organizacional Causada pela Introdução de Universidade Corporativa”, construída e validada por Silva (2006). A análise de consistência interna feita com os dados da pesquisa da Eletronorte obteve índices de confiabilidade (Alpha de Cronbach) ainda maiores do que os conseguidos originalmente pelo autor quando da construção do instrumento.

Os resultados encontrados nesta pesquisa não podem ser generalizados. Contudo, eles servem para contestar as afirmações feitas por outros autores como Marcondes e Paiva (2001) e Dengo (2002), cujos resultados de pesquisa apontaram resultados pouco otimistas com relação às diferenças trazidas na implantação de uma universidade corporativa. 


\section{REFERÊNCIAS}

ALBRECHET, K. O gerente e o estresse. Rio de Janeiro: Zahar, 1988.

ALPERSTEDT, C. Universidades Corporativas: Discussão e Proposta de uma Definição. In: ENCONTRO NACIONAL DA ANPAD XXIV. 2000, Florianópolis.

ALPERSTEDT, C., Plonski, G.. As Universidades Corporativas e sua Inserção no Setor de Educação Superior. In: ENCONTRO NACIONAL DA ANPAD XXV. 2001, Campinas.

ARAÚJO, L. C. G. Mudança organizacional na administração pública federal brasileira. 1982. 307 f. Tese (Doutorado em Administração)-Escola de Administração de São Paulo, São Paulo, 1982.

BONILAURI, A. R. C. Educação corporativa: adaptabilidade e flexibilidade. In: Brasil. Ministério do Desenvolvimento, Indústria e Comércio Exterior. Secretaria de Tecnologia Industrial (Org.). O futuro da indústria: educação corporativa. Brasília: CNI-IEL, 2005. p. 29-34.

BRASIL, Constituição da República Federativa do. 1988.

BRUNO-FARIA, M. F. Criatividade inovação e mudança organizacional. In: LIMA, S. M. V. (Org.). Mudança Organizacional: teoria e gestão. Rio de Janeiro: FGV, 2003. cap. 3, p. 111141.

CRUZ NETO, O. Trabalho de campo como descoberta e criação. In: MINAYO, M. C. S. (Org). Pesquisa social: teoria, método, e criatividade. Petrópolis: Vozes, 1994. cap. 3, p. 5166.

DENGO, N. Universidades Corporativas: modismo ou inovação? In: ENCONTRO NACIONAL DA ANPAD XXVI. 2002, Salvador.

EBOLI, M. P. Educação corporativa no Brasil: mitos e verdades. São Paulo: Gente, 2004.

GASKELL, G. Entrevistas individuais e grupais. In: BAUER, Martin W.; GASKELL, George (Orgs.). Pesquisa Qualitativa com Texto, Imagem e Som. Petrópolis: Vozes, 2002.

GREENWOOD, R.; HININGS, C.R. Understanding Radical Organizational Change: bringing together the old and the new institutionalism. Academy of Management Review, 21, 4, 1022-1054, 1996.

HAMMER, M. A essência da nova organização. In: DUCKER, P. (Org.). A organização do futuro. São Paulo: Futura. 2003. p. 41-48.

HERNANDEZ, J. M. C.; CALDAS, M. P.. Resistência à mudança: uma abordagem individual. In: Encontro da Associação Nacional dos Programas de Pós-Graduação em Administração, $2^{\circ}$, 2000, Florianópolis, Santa Catarina. ENANPAD. Resumo dos Trabalhos. Rio de Janeiro: Metrópole. 
LEAL, A. P. Universidade Corporativa e controle social: as faces da habilitação e instrumentalização do sujeito trabalhador em uma organização multinacional da área logística. Dissertação (Mestrado em Administração) - Universidade Federal do Paraná, Curitiba, 2003.

LIMA, S. M. V.; BRESSAN, C. L. Mudança organizacional: uma introdução. In: LIMA, S. M. V. (Org.). Mudança organizacional: teoria e gestão. Rio de Janeiro: FGV, 2003. cap. 1, p. 17-63.

MARCONDES, R. C.; PAIVA, J. A. de. Afinal, a universidade corporativa é uma T\&D revisada? In: ENCONTRO NACIONAL DA ANPAD XXV. 2001, Campinas.

MEISTER, J. Educação corporativa. A gestão do capital intelectual através das universidades corporativas. São Paulo: Makron, 1999.

NADLER, D.A.; TUSHMAN, M.L. Types of Organizational Change: from incremental improvement to discontinuous transformation. In: NADLER, D.A.; SHAW, R.B.; WALTON, A.E. (Orgs.). Descontinuous Change: leading organizational transformation. San Francisco: Jossey-Bass Publishers, 1994.

NEIVA, E. R. Percepção de mudança individual e organizacional: o papel das attitudes e das características organizacionais. 2004. 270 f. Tese (Doutorado em Ciência - Psicologia) - Instituto de Psicologia, Universidade de Brasília, Brasília, 2004.

PEAK, M. H. Go corporate U. Management Review, v.86, n.2, p. 33-37, Feb, 1997.

QUEIROZ, A. M.; FACHIN, R. C.; SANTANNA, A. S. Universidades corporativas: do sonho da implantação ao desafio da gestão: um estudo de caso. In: ENCONTRO DA ASSOCIAÇÃO NACIONAL DE PÓS-GRADUAÇÃO E PESQUISA EM ADMINISTRAÇÃO, 28., 2004, Curitiba. Anais eletrônicos. Rio de Janeiro: ANPAD, 2004. $1^{\circ} \mathrm{CD}-\mathrm{ROM}$.

RICHARDSON, R. J. Pesquisa Social: Métodos e Técnicas; 3. ed. São Paulo/SP: Atlas, 1999.

ROBBINS, S. P. Mudança organizacional e administração do estresse. In: Comportamento organizacional. Rio de Janeiro, LTC, 1999. p. 394-423.

SILVA, R. C. J. da. Construção e Validação de Escala de Medida de Mudança Organizacional Causada pela Implantação de uma Universidade Corporativa. Dissertação (Mestrado em Gestão Social e Trabalho) - Programa de Pós-Graduação em Administração, Universidade de Brasília, Brasília, 2006.

SOARES, M. F. L. Universidades corporativas: vetores de uma cultura tecnológica. In: BRASIL. Ministério do Desenvolvimento, Indústria e Comércio Exterior. Secretaria de Tecnologia Industrial (Org.). Educação corporativa: contribuição para a competitividade. Brasília: Petrobrás: CNI, 2004. p. 165-198.

TARAPANOFF, K. Panorama da Educação Corporativa no Contexto Internacional. IN: Educação Corporativa: contribuição para a competitividade, Org. SCT. Brasília: Petróleo Brasileiro e CNI, 2004. 
VARGAS $^{\mathrm{a}}$, M. R. M. Educação a Distância no Contexto da Mudança Organizacional. In: VALLE, S.M.L. (Org.) Mudança Organizacional: teoria e gestão. Rio de Janeiro, FGV, 2003.

VARGAS $^{\mathrm{b}}$, M. R. M. Universidade Corporativa: diferentes modelos de configuração. Revista de Administração, v.38, n.4 p 373-379, out./nov/dez 2003, São Paulo.

VARGAS, M. R. M.; ABBAD, G. da S. Bases Conceituais de TD\&E. In: BORGESANDRADE, J.E.; ABADD, G.S.; MOURÃO, L. (Orgs.). Treinamento, Desenvolvimento e Educação em Organizações e Trabalho: fundamentos para a gestão de pessoas. Porto Alegre: Artmed, 2006.

VERGARA, S. C. Projetos e relatórios de pesquisa em administração. 7ed. São Paulo: Atlas, 2006

VITELLI, A. P. D. Universidades corporativas: fonte de vantagem competitiva para as organizações na era do conhecimento? In: ENCONTRO NACIONAL DA ANPAD XXIV. 2000, Florianópolis.

WIND, J. Y.; MAIN, J. Provocar mudanças: como as melhores empresas estão se preparando para o século XXI. Rio de Janeiro: Qualitymark, 1988.

WOOD JR., T. (Coord.). Mudança organizacional. 4. ed. São Paulo: Atlas, 2004. 
ANEXO A - POP-UP DE DIVULGAÇÃO DA PESQUISA

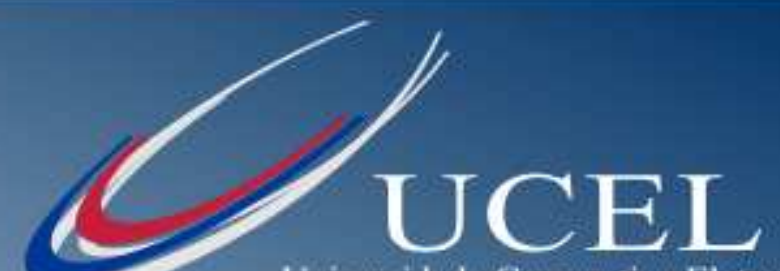

Universidade Corporativa Eletronorte

Mudanças causadas pela implantação da

Unjversidade Corporativa

Visando contribuir ainda mais para $o$ aperfeiçoamento contínuo dos(as) empregados(as)

da Eletronorte, queremos saber a sua opinião sobre as mudanças ocorridas após a implantação da Universidade Corporativa.

Se você trabalha há mais de 6 anos na Eletronorte, por favor, ajude-nos clicando no link abaixo, até o dia $\mathbf{2 1}$ de outubro, para responder a esta pesquisa.

Sua participação é muito importante!

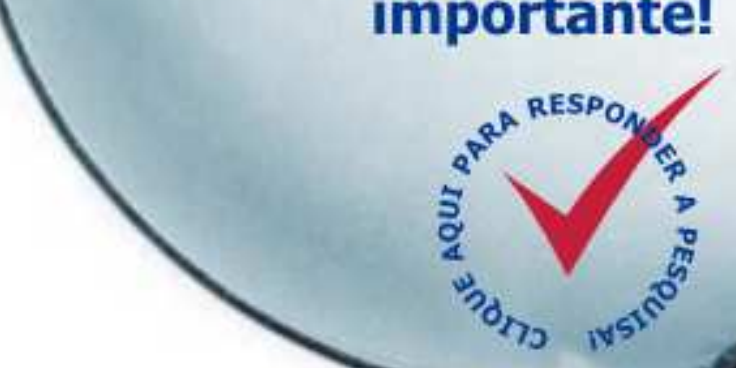


ANEXO B - INSTRUMENTO DE PESQUISA

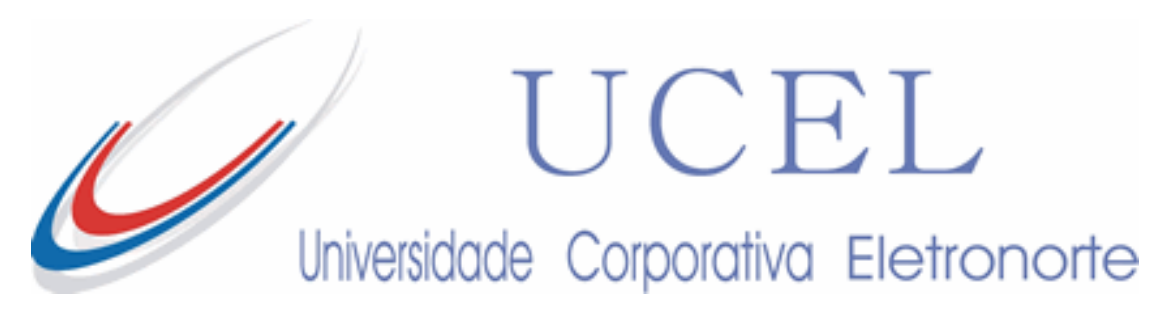

Percepção de mudança organizacional causada pela implantação da UCEL

Visando contribuir para o aperfeiçoamento contínuo dos (as) empregados (as) da Eletronorte queremos saber sua opinião sobre as mudanças ocorridas após a implantação da Universidade Corporativa.

Para isso estamos disponibilizando a pesquisa validada por Silva 2006.

Por favor, somente responda a este questionário se você trabalha há mais de 6 anos na Eletronorte.

A seguir estão listadas várias mudanças que podem ter ocorrido na Empresa a partir da implantação da Universidade Corporativa. Pense na Eletronorte e responda às frases de acordo com a escala apresentada. 


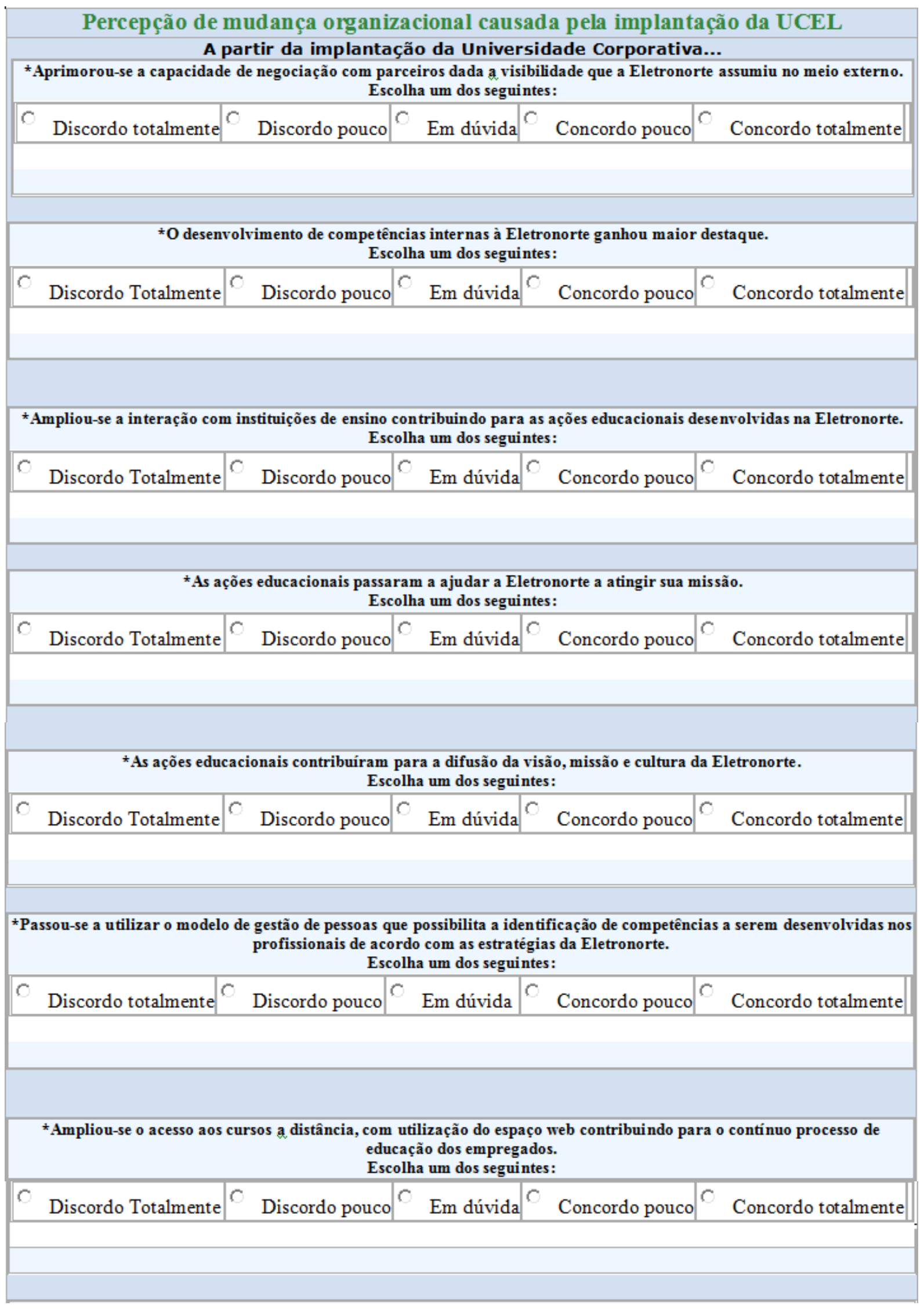




\begin{tabular}{|c|c|c|c|c|c|}
\hline \multicolumn{6}{|c|}{$\begin{array}{l}\text { *Ampliaram-se os canais de comunicação entre os empregados na Eletronorte. } \\
\text { Escolha um dos seguintes: }\end{array}$} \\
\hline$C$ & Discordo totalmente & Discordo pouco & Em dúvida & C Concordo pouco & Concordo totalmente \\
\hline \multicolumn{6}{|c|}{$\begin{array}{c}\text { *Houve uma maior aproximação entre stakeholders (clientes, fornecedores, empregados etc) e a Eletronorte trazendo uma } \\
\text { melhoria da imagem da Empresa. } \\
\text { Escolha um dos seguintes: }\end{array}$} \\
\hline$c$ & Discordo totalmente & D Discordo pouco & Em dúvida & C Concordo pouco & C Concordo totalmente \\
\hline \multicolumn{6}{|c|}{$\begin{array}{l}\text { *Ampliaram-se as oportunidades de aprendizagem na Eletronorte reforçando a idéia de educação permanente. } \\
\text { Escolha um dos seguintes: }\end{array}$} \\
\hline$c$ & Discordo totalmente & D Discordo pouco & Em dúvida & Concordo pouco & Concordo totalmente \\
\hline \multicolumn{6}{|c|}{$\begin{array}{l}\text { *A formação de profissionais passou a ser feita de acordo com as es tratégias organizacionais. } \\
\text { Escolha um dos seguintes: }\end{array}$} \\
\hline$r$ & Discordo totalmente & Discordo pouco & Em dúvida & Concordo pouco & Concordo totalmente \\
\hline \multicolumn{6}{|c|}{$\begin{array}{l}\text { *Houve uma maior contribuição para a aquisição de competências emergentes pela Eletronorte. } \\
\text { Escolha um dos seguintes: }\end{array}$} \\
\hline C & Discordo totalmente & Discordo pouco & Em dúvida & Concordo pouco & Concordo totalmente \\
\hline \multicolumn{6}{|c|}{$\begin{array}{c}\text { *As ações educacionais passaram a atender às estra tégias empresariais. } \\
\text { Escolha um dos seguintes: }\end{array}$} \\
\hline $\mathrm{C}$ & Discordo Totalmente & D Discordo pouco & Em dúvida & Concordo pouco & Concordo totalmente \\
\hline \multicolumn{6}{|c|}{$\begin{array}{l}\text { *A Eletronorte implantou o modelo de gestão por competência contribuindo para a realização das metas organizacionais } \\
\text { Escolha um dos seguintes: }\end{array}$} \\
\hline $\mathrm{C}$ & Discordo totalmente & Discordo pouco & Em dúvida & Concordo pouco & Concordo totalmente \\
\hline \multicolumn{6}{|c|}{$\begin{array}{l}\text { *A interação com culturas diferentes (Eletronorte versus instituições de ensino superior) passou a ser mais constante. } \\
\text { Escolha um dos seguintes: }\end{array}$} \\
\hline$c$ & Discordo totalmente & D Discordo pouco & Em dúvida & Concordo pouco & C Concordo totalmente \\
\hline
\end{tabular}




\begin{tabular}{|c|c|c|c|c|}
\hline \multicolumn{5}{|c|}{$\begin{array}{l}\text { *Ampliou-se o número de serviços prestados à com unidade com a conseqüente melhoria da imagem. } \\
\text { Escolha um dos seguintes: }\end{array}$} \\
\hline C Discordo totalmente & Discordo pouco & Em dúvida & C Concordo pouco & Concordo totalmente \\
\hline \multicolumn{5}{|c|}{$\begin{array}{l}\text { *Os seus empregados passaram a ter mais orgulho de trabalhar na Eletronorte da da a melhoria de sua imagem no contexto } \\
\text { externo. } \\
\text { Escolha um dos seguintes: }\end{array}$} \\
\hline C Discordo totalmente & Discordo pouco & Em dúvida & Concordo pouco & Concordo totalmente \\
\hline \multicolumn{5}{|c|}{$\begin{array}{l}\text { *Facilitou-se o aprendizado contínuo dos empregados na Eletronorte reforçando a idéia de educação permanente. } \\
\text { Escolha um dos seguintes: }\end{array}$} \\
\hline C Discordo totalmente & $C$ Discordo pouco & Em dúvida & Concordo pouco & Concordo totalmente \\
\hline \multicolumn{5}{|c|}{$\begin{array}{l}\text { *A Eletronorte ganhou visibilidade no mercado em que atua, em função de suas ações destinadas a contribuir para o } \\
\text { desenvolvimento de seus empregados. } \\
\text { Escolha um dos seguintes: }\end{array}$} \\
\hline Discordo totalmente & Discordo pouco & Em dúvida & C Concordo pouco & Concordo totalmente \\
\hline \multicolumn{5}{|c|}{$\begin{array}{l}\text { *Houve uma maior aproximação da área de gestão de pessoas com as áreas negociais na Eletronorte. } \\
\text { Escolha um dos seguintes: }\end{array}$} \\
\hline$C$ Discordo totalmente & $C$ Discordo pouco & Em dúvida & C Concordo pouco & C Concordo totalmente \\
\hline \multicolumn{5}{|c|}{$\begin{array}{l}\text { *Valorizou-se mais o conhecimento produzido pelas pessoas na Eletronorte. } \\
\text { Escolha um dos seguintes: }\end{array}$} \\
\hline$C$ Discordo totalmente & C Discordo pouco & Em dúvida & Concordo pouco & C Concordo totalmente \\
\hline \multicolumn{5}{|c|}{$\begin{array}{l}\text { *Foram conquistados novos clientes devido a melhoria da imagem da Eletronorte. } \\
\text { Escolha um dos seguintes: }\end{array}$} \\
\hline C Discordo totalmente & D Discordo pouco & Em dúvida & C Concordo pouco & Concordo totalmente \\
\hline \multicolumn{5}{|c|}{$\begin{array}{l}\text { *Expandiu-se a cultura de aprendizagem ao longo da vida a partir da disseminação do conhecimento produzido por } \\
\text { indivíduos e grupos na Eletronorte. } \\
\text { Escolha um dos seguintes: }\end{array}$} \\
\hline C Discordo totalmente & C Discordo pouco & Em dúvida & C Concordo pouco & Concordo totalmente \\
\hline
\end{tabular}




\begin{tabular}{|c|c|c|c|c|c|}
\hline \multicolumn{6}{|c|}{$\begin{array}{l}\text { *Passou-se a utilizar o modelo de gestão que valoriza as competências da Eletronorte e dos empregados como base para } \\
\text { definição de ações de educação corporativa. } \\
\text { Escolha um dos seguintes: }\end{array}$} \\
\hline 0 & Discordo totalmente & Discordo pouco & Em dúvida & Concordo pouco & Concordo totalmente \\
\hline \multicolumn{6}{|c|}{$\begin{array}{c}\text { *Houve uma maior contribuição para a aprendizagem organizacional a partir da disseminação do conhecimento produzido } \\
\text { por indivíduos e grupos na Eletronorte. } \\
\text { Escolha um dos seguintes: }\end{array}$} \\
\hline$c$ & Discordo totalmente & C Discordo pouco & Em dúvida & Concordo pouco & Concordo totalmente \\
\hline \multicolumn{6}{|c|}{$\begin{array}{l}\text { *Houve uma maior aproximação entre a Eletronorte e instituições de ensino. } \\
\text { Escolha um dos seguintes: }\end{array}$} \\
\hline$c$ & Discordo totalmente & C Discordo pouco & Em dúvida & Concordo pouco & Concordo totalmente \\
\hline \multicolumn{6}{|c|}{$\begin{array}{l}\text { *A Eletronorte passou a promover ações de responsabilidade social tornando-se mais conhecida. } \\
\text { Escolha um dos seguintes: }\end{array}$} \\
\hline 0 & Discordo totalmente & D Discordo pouco & Em dúvida & Concordo pouco & $C$ Concordo totalmente \\
\hline
\end{tabular}

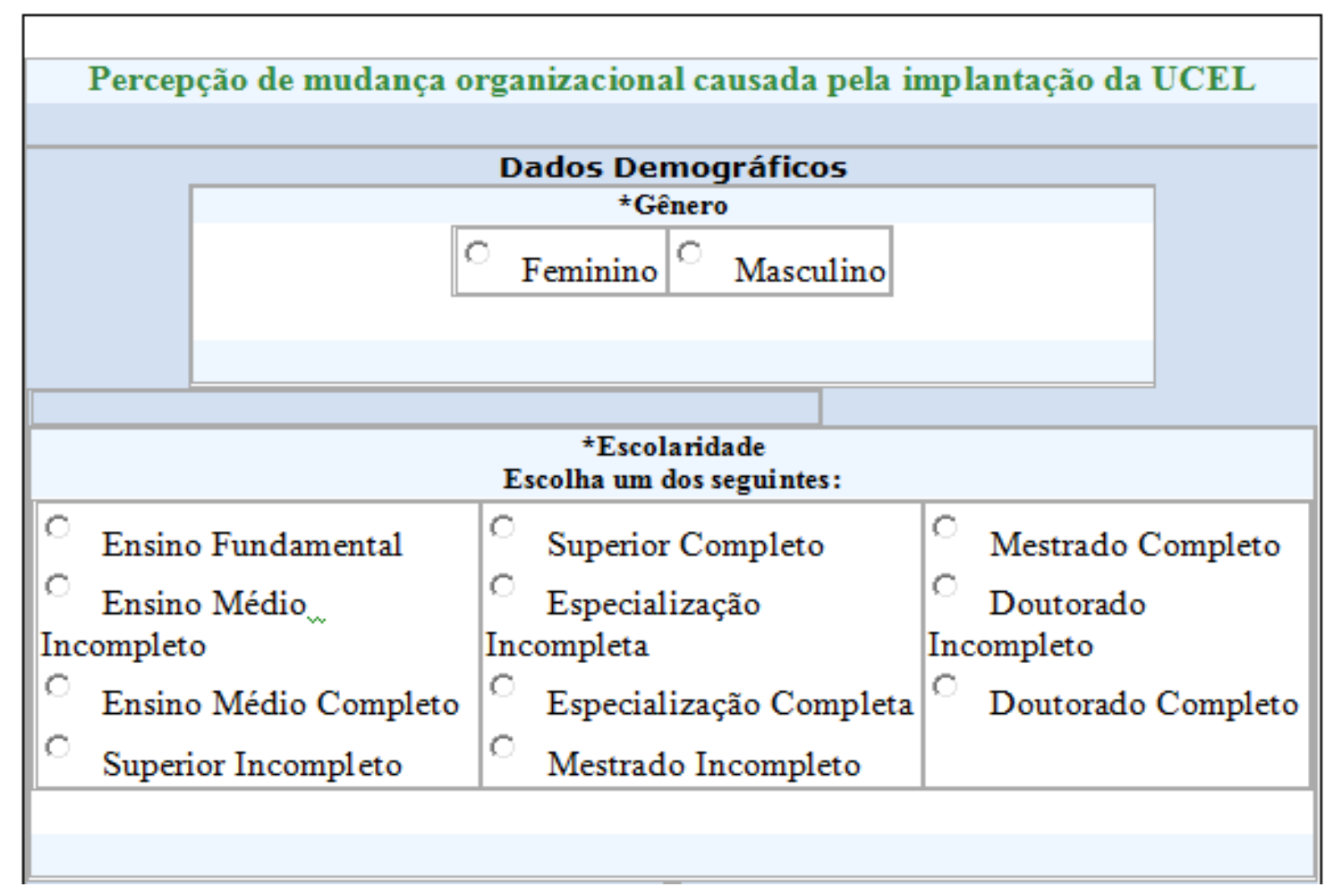




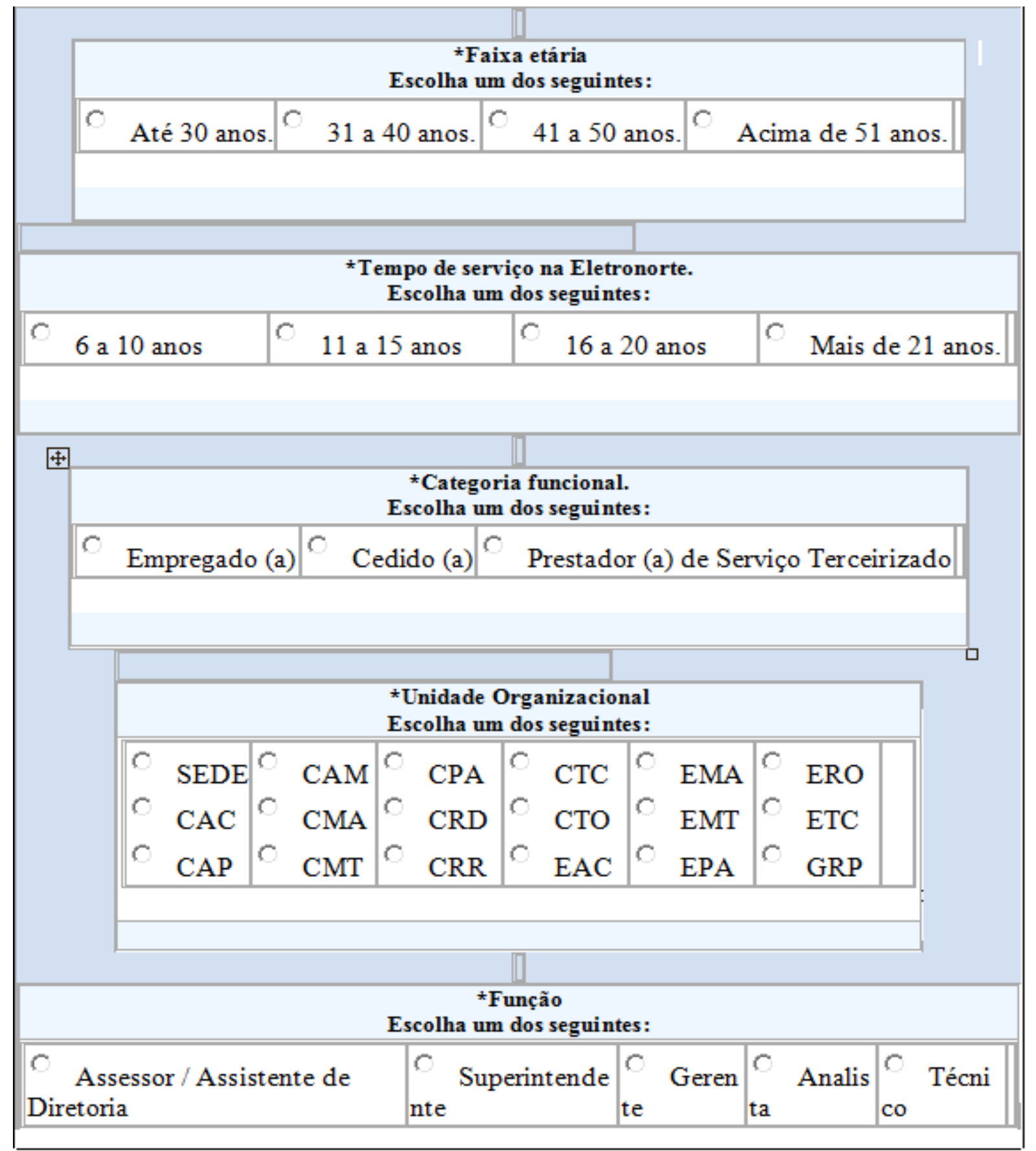

